\title{
Progress and Opportunities in the Characterization of Cellulose - An Important Regulator of Cell Wall Growth and Mechanics
}

\author{
Sintu Rongpipi ${ }^{1}$, Dan $Y^{1}{ }^{1}$, Enrique D. Gomez ${ }^{1,2,3 *}$ and Esther W. Gomez ${ }^{1,4 *}$ \\ ${ }^{1}$ Department of Chemical Engineering, The Pennsylvania State University, University Park, PA, United States, ${ }^{2}$ Department \\ of Materials Science and Engineering, The Pennsylvania State University, University Park, PA, United States, ${ }^{3}$ Materials \\ Research Institute, The Pennsylvania State University, University Park, PA, United States, ${ }^{4}$ Department of Biomedical \\ Engineering, The Pennsylvania State University, University Park, PA, United States
}

\section{OPEN ACCESS}

Edited by:

Laura Elizabeth Bartley, The University of Oklahoma,

United States

Reviewed by:

Doriano Lamba,

Italian National Research Council, Italy Yunqiao Pu,

Oak Ridge National Laboratory (DOE), United States

*Correspondence: Enrique D. Gomez edg12@psu.edu Esther W. Gomez ewg10@psu.edu

Specialty section: This article was submitted to

Plant Cell Biology,

a section of the journal

Frontiers in Plant Science

Received: 29 June 2018 Accepted: 06 December 2018

Published: 01 March 2019

Citation:

Rongpipi S, Ye D, Gomez ED and Gomez EW (2019) Progress and Opportunities in the Characterization of Cellulose An Important Regulator of Cell Wall

Growth and Mechanics.

Front. Plant Sci. 9:1894. doi: 10.3389/fp/s.2018.01894
The plant cell wall is a dynamic network of several biopolymers and structural proteins including cellulose, pectin, hemicellulose and lignin. Cellulose is one of the main load bearing components of this complex, heterogeneous structure, and in this way, is an important regulator of cell wall growth and mechanics. Glucan chains of cellulose aggregate via hydrogen bonds and van der Waals forces to form long thread-like crystalline structures called cellulose microfibrils. The shape, size, and crystallinity of these microfibrils are important structural parameters that influence mechanical properties of the cell wall and these parameters are likely important determinants of cell wall digestibility for biofuel conversion. Cellulose-cellulose and cellulose-matrix interactions also contribute to the regulation of the mechanics and growth of the cell wall. As a consequence, much emphasis has been placed on extracting valuable structural details about cell wall components from several techniques, either individually or in combination, including diffraction/scattering, microscopy, and spectroscopy. In this review, we describe efforts to characterize the organization of cellulose in plant cell walls. X-ray scattering reveals the size and orientation of microfibrils; diffraction reveals unit lattice parameters and crystallinity. The presence of different cell wall components, their physical and chemical states, and their alignment and orientation have been identified by Infrared, Raman, Nuclear Magnetic Resonance, and Sum Frequency Generation spectroscopy. Direct visualization of cell wall components, their network-like structure, and interactions between different components has also been made possible through a host of microscopic imaging techniques including scanning electron microscopy, transmission electron microscopy, and atomic force microscopy. This review highlights advantages and limitations of different analytical techniques for characterizing cellulose structure and its interaction with other wall polymers. We also delineate emerging opportunities for future developments of structural characterization tools and multi-modal analyses of cellulose and plant cell walls. Ultimately, elucidation of the structure of plant cell walls across multiple length scales will be imperative for establishing structure-property relationships to link cell wall structure to control of growth and mechanics.

Keywords: cellulose microfibrils, cellulose allomorphs, cellulose crystallinity, X-ray diffraction, X-ray scattering, vibrational spectroscopy, nuclear magnetic resonance spectroscopy, atomic force microscopy 


\section{INTRODUCTION}

The plant cell wall is a complex, heterogeneous network of several polymers and structural proteins. It provides mechanical strength and plays key roles in plant growth, cell differentiation, intercellular communication, water movement, and defense (Cosgrove, 2005). Most higher plants contain both primary and secondary cell walls. The primary cell wall is a thin, flexible, and highly hydrated structure that surrounds the growing cell, while secondary cell wall is a stronger and more rigid structure that starts to deposit when the cell ceases to grow. These cell wall types differ in function, rheological and mechanical properties, and in the arrangement, mobility, and structure of matrix polymers (Cosgrove and Jarvis, 2012). Primary walls are comprised of mainly cellulose, pectin, and xyloglucans with lesser amounts of arabinoxylans and structural proteins. Hydration of the pectin matrix facilitates the slippage and separation of cellulose microfibrils during expansive growth. The strength and rigidity of secondary walls come from a more oriented arrangement of cellulose microfibrils and the presence of lignin. Secondary cell walls are composed mainly of cellulose, lignin, xylans, and glucomannans, and are also less hydrated when compared to primary walls (Cosgrove and Jarvis, 2012).

Cellulose is the primary structural component responsible for much of the mechanical strength of the cell wall. The distribution and orientation of cellulose microfibrils within the cell wall contribute to the control of cell growth. The alignment of microfibrils provides the cell with mechanical anisotropy that enables preferential expansion in one direction (Jordan and Dumais, 2010). In addition to its biological significance, cellulose is an important raw material for textiles, paper, construction materials, and many industrially important chemical derivatives. It is also the most abundant carbohydrate on earth, and is a promising source for renewable energy.

The chemical structure of cellulose consists of linear chains of glucose units linked by $\beta-1,4$-glycosidic bonds. Glucan chains of cellulose aggregate via hydrogen bonds and van der Waals forces to form a long thread-like crystalline structure called a cellulose microfibril (Harris et al., 2010). Important structural properties of cellulose include crystallite shape and size and crystallinity. Many different analytical techniques have been employed to study the structure and assembly of cellulose microfibrils in cell walls, yet a comprehensive understanding over multiple length scales remains elusive.

Structural characterization approaches currently used to examine plant cell walls are based on four broad categories of techniques: diffraction/scattering, spectroscopy, microscopy, and physicochemical assays. Figure $\mathbf{1}$ highlights these structural characterization tools and the length scales at which they can reveal information about cell wall structure. Solid state ${ }^{13} \mathrm{C}$ nuclear magnetic resonance (NMR) studies led to the discovery of two cellulose allomorphs (VanderHart and Atalla, 1984). The crystal structures of cellulose $I \alpha$ and $I \beta$ were then determined with the help of X-ray, electron, and neutron diffraction studies (Sugiyama et al., 1991b; Abe et al., 1997; Nishiyama et al., 2002, 2003). Further details about structural differences between these two forms were described by Raman and Fourier-transform infrared (FTIR or IR) spectroscopy, which indicated that glucan chains have similar conformations but differ in hydrogen bonding patterns (Atalla and VanderHart, 1999). The selective detection of cellulose allomorphs is also possible through an emerging spectroscopic technique called sum frequency generation (SFG) spectroscopy (Kim et al., 2013). Beyond the crystal structure, X-ray diffraction (XRD), NMR, and IR and Raman spectroscopy are widely used to estimate the amount of crystalline cellulose present (degree of crystallinity) in plant cell walls. Crystallinity is also determined by some physico-chemical methods, such as the Updegraff method, iodine adsorption, sorption of water vapor, and enthalpy of wetting.

The supramolecular structure of the primary cell wall has been widely characterized by microscopic techniques. Many structural parameters such as crystallite size as well as fibril dimensions, cross-section, and spacing have been directly visualized (Cox and Juniper, 1973; Davies and Harris, 2003; Ding et al., 2014). Electron microscopy has been most widely used to image the fibrillar features of cellulose, but can nevertheless introduce artifacts during sample preparation. Therefore, other microscopic techniques, including scanning probe microscopy, fluorescence microscopy, confocal microscopy, and polarized light microscopy (Abe et al., 1997; Thomson et al., 2007; Choong et al., 2016), are now being explored to visualize the cell wall in its native state with minimal sample preparation.

Complementary to microscopy, the dimensions and packing of cellulose microfibrils are also examined by scattering and spectroscopic techniques (Fernandes et al., 2011; Newman et al., 2013; Zhang et al., 2016). Due to the minimal sample preparation required, scattering is ideal for characterizing the cell wall in its native state. Scattering approaches also offer the benefit of enabling investigation of a large size range, thus allowing for the arrangement of individual microfibrils as well as the aggregates of microfibrils to be examined.

Altogether, the combination of various techniques to characterize the organization of cell wall components opens the door to the examination of interactions between cellulose and other cell wall polysaccharides, potentially revealing various aspects of cell wall assembly (Martínez-Sanz et al., 2015a). For example, a combination of different imaging techniques such as atomic force microscopy (AFM), transmission electron microscopy (TEM), field emission scanning electron microscopy (FESEM), and confocal microscopy has been used to examine alteration in cellulose microfibril arrangement in the primary cell walls of the Arabidopsis xxt1 xxt2 double mutant that lacks detectable xyloglucan (Xiao et al., 2016). The study revealed that cellulose microfibrils are highly aligned in xyloglucan mutants as compared to those in wild type, suggesting that xyloglucan functions as a spacer between cellulose microfibrils in the primary cell wall.

This review summarizes techniques that are used for the characterization of structure and interactions of cellulose in plant cell walls, particularly cellulose crystallinity, microfibril size, and spatial organization along with cellulose-cellulose and cellulose-matrix interactions. We discuss both established and emerging techniques used for the molecular and microstructural characterization of cellulose structure, and highlight the strengths 

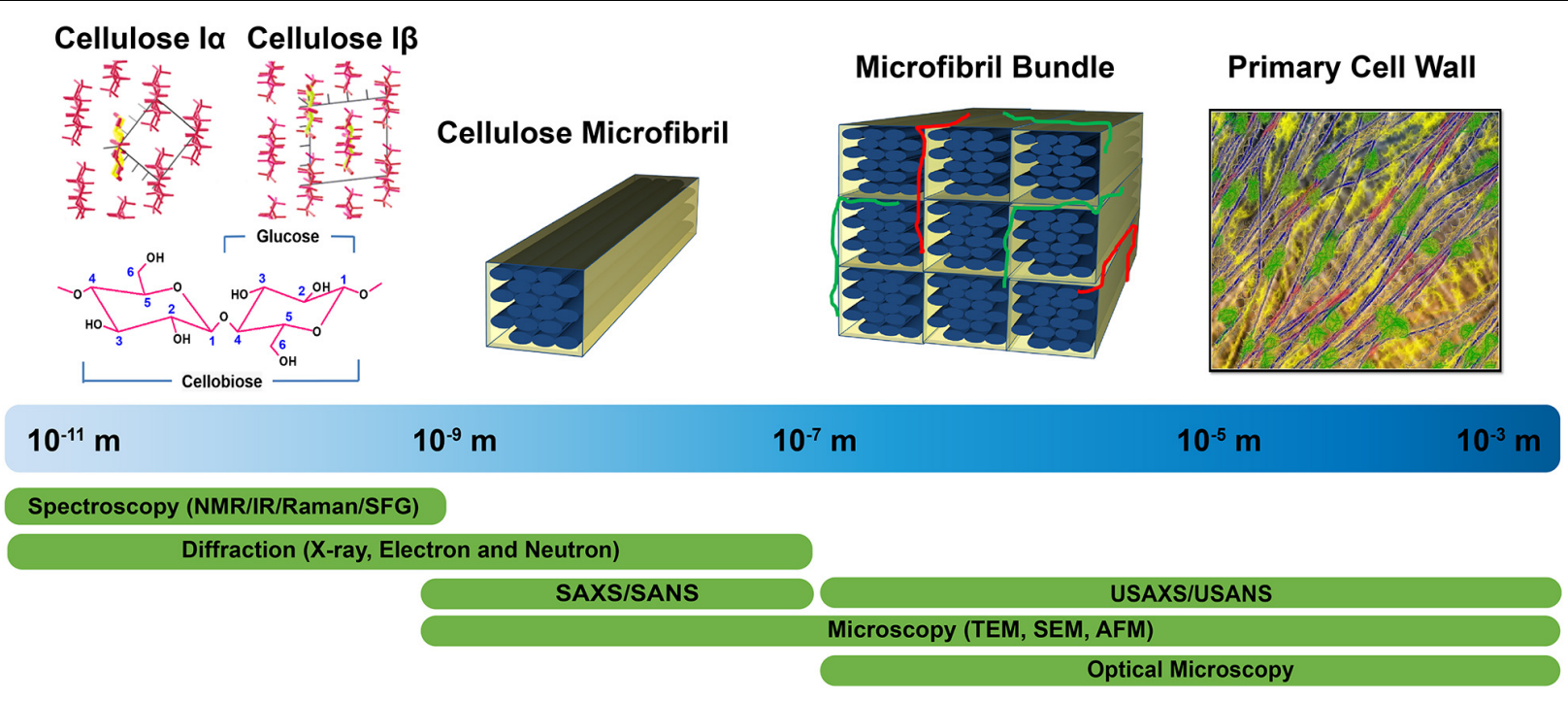

FIGURE 1 | Tools enabling characterization of the primary cell wall at different length scales. Crystal structures of cellulose l $\alpha$ and $\mid \beta$ are reprinted with permission from Nishiyama et al. (2003). Crystal Structure and Hydrogen Bonding System in Cellulose l $\alpha$ from Synchrotron X-ray and Neutron Fiber Diffraction. Journal of the American Chemical Society 125, 14300-14306. Copyright (C) 2003 American Chemical Society. Primary cell wall is reprinted with permission from Cosgrove (2014). Re-constructing our models of cellulose and primary cell wall assembly. Current Opinion in Plant Biology 22, 122-131. Copyright (C) 2014 Elsevier Ltd. Schematic inspired by Martínez-Sanz et al. (2015a). Application of X-ray and neutron small angle scattering techniques to study the hierarchical structure of plant cell walls: A review. Carbohydrate Polymers 125, 120-134.

and limitations of each technique. In addition, the review introduces several characterization techniques that are presently not widely used for studying plant cell walls, but given their capabilities, might prove to be powerful tools to reveal new information regarding structure and organization.

\section{CRYSTALLINE STRUCTURE OF NATIVE CELLULOSE AND ITS ALLOMORPHS}

Six polymorphic forms of cellulose (Cellulose I, II, III I III II, $\mathrm{IV}_{\mathrm{I}}$, and $\left.\mathrm{IV}_{\mathrm{II}}\right)$ that are interconvertible have been identified (O'Sullivan, 1997). Natural cellulose is found in the form of cellulose I, which has two allomorphs - cellulose I $\alpha$ and cellulose I $\beta$ (VanderHart and Atalla, 1984; Sugiyama et al., 1991a). Cellulose $\mathrm{I} \alpha$ is the dominant form in primitive organisms like bacteria and algae while Cellulose $\mathrm{I} \beta$ is dominant in higher plants. The existence of these two forms was established by spectroscopic techniques while their lattice structures were revealed by diffraction techniques. Both techniques are widely used to identify the two forms of cellulose in plant cell walls and they are also used to quantify the relative abundances of the cellulose forms. This section highlights studies that revealed the cellulose unit cell parameters by diffraction techniques, and also discusses methods for identifying the two different forms (cellulose $\mathrm{I} \alpha$ and $\mathrm{I} \beta$ ) most commonly found in nature.

\section{Revealing the Unit Cell Parameters of Cellulose}

The unit cell parameters of the two allomorphs of native cellulose were established through X-ray, electron, and neutron diffraction techniques. These techniques work on the principle of Bragg's law to determine the $d$-spacing of atomic planes using electromagnetic waves. Thus, although diffraction data is often represented as intensity versus scattering angle $\theta$, it is useful to represent it as a function of scattering vector $q$ instead to normalize for the radiation wavelength $\lambda(q=4 \pi \sin (\theta / 2) / \lambda)$. Diffraction techniques are used for two main purposes: (i) determination of the three-dimensional structure of molecules and thus their crystallographic form, and (ii) assessment of the degree of crystallinity. Due to the weak diffraction from primary cell walls, the majority of studies on the unit cell parameters have focused on cellulose from algae, bacteria, and secondary cell walls. We briefly discuss these findings in this section, but also emphasize available data on primary cell walls.

The first X-ray diffraction (XRD) patterns of cellulose fibers were collected from wood, hemp, and bamboo in 1913 (Nishikawa and Ono, 1913). The quantification of cellulose crystal parameters began with data derived from XRD of plant fibers including Ramie, hemp, flax, spruce, and cotton (Sponsler, 1928). The lattice parameters of cellulose from different sources like algae, bacteria, and plants are well summarized (O’Sullivan, 1997).

Neutron diffraction (Beg et al., 1974; Ahmed et al., 1976) and electron diffraction (Honjo and Watanabe, 1958) studies have provided complementary structural information about cellulose I, enabling improvement of structural models developed from XRD data. Specifically, synchrotron X-ray techniques and neutron diffraction have enabled near atomic resolution. High-resolution synchrotron 2D data from oriented fibers of Halocynthia, which is nearly pure cellulose I $\beta$, is shown in Figure 2 (Nishiyama et al., 2002). The data 


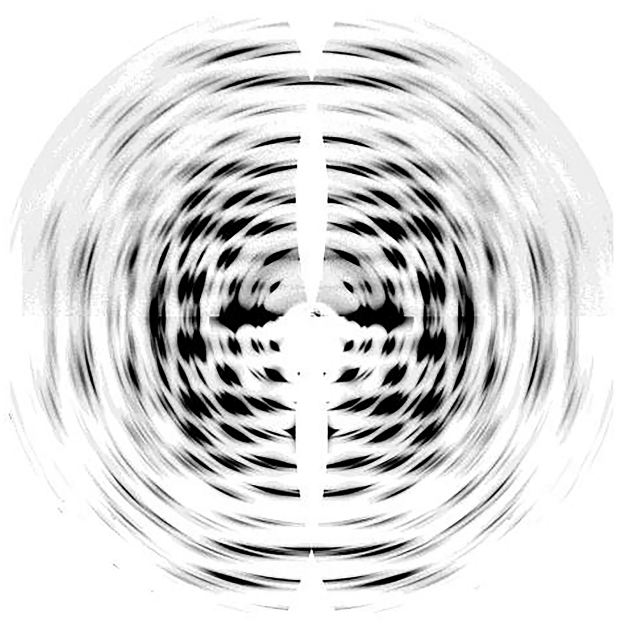

FIGURE 2 | Synchrotron XRD 2D pattern of Halocynthia cellulose I $\beta$. Reprinted with permission from Nishiyama et al. (2002). Crystal Structure and Hydrogen-Bonding System in Cellulose I $\beta$ from Synchrotron X-ray and Neutron Fiber Diffraction. Journal of the American Chemical Society 124 , 9074-9082. Copyright (C) 2002, American Chemical Society.

have a resolution better than $1 \AA$ with more than 300 unique reflections. The high resolution of this data was important to determine atomic coordinates in the unit cell of cellulose I $\beta$.

Synchrotron X-ray experiments can provide accurate locations for carbon and oxygen atoms, but cannot do so for hydrogen atoms due to their small X-ray scattering crosssections. Neutron diffraction of intra-crystalline deuterated cellulose samples has revealed important information about the intermolecular hydrogen bond network in cellulose I $\alpha$ and I $\beta$ (Nishiyama et al., 2002, 2003). These experiments reveal that no inter-sheet hydrogen bonds exist in crystals of cellulose $\mathrm{I} \alpha$ and I $\beta$, and the sheets are held together by hydrophobic interactions and weak $\mathrm{C}-\mathrm{H}$. . O bonds. The hydrogen bonds O3-H...O5 could be visualized through Fourier difference maps calculated from neutron diffraction data. These maps give information about missing atoms in the crystal structure by subtracting the calculated structure factors from observed ones. These studies also showed that within each cellulose sheet the intramolecular hydrogen bond at $\mathrm{O} 3$ is well organized while the intermolecular hydrogen bond for $\mathrm{O} 2$ and $\mathrm{O} 6$ is disordered over two possible networks. Furthermore, the relative occurrence of these networks differs in the two cellulose allomorphs. Also, the bond length and bond angle of the intrachain $\mathrm{O} 3-\mathrm{H} \cdots \mathrm{O} 5$ hydrogen bonds alternate between two different geometries in cellulose $\mathrm{I} \alpha$ and $\mathrm{I} \beta$. While the alternating geometry of the bond is along the same chain in $\mathrm{I} \alpha$, it is between two distinct chains in $\mathrm{I} \beta$.

Electron diffraction has made significant contributions in differentiating between the structures of the two crystalline phases of native cellulose, and established that cellulose I $\alpha$ and I $\beta$ have different lattice systems (Sugiyama et al., 1991a,b). Cellulose I $\alpha$ has a triclinic lattice with one chain per unit cell and cellulose
I $\beta$ has a monoclinic lattice with two chains per unit cell, as shown in Figure 3. This technique has the advantage of producing intense diffraction patterns from a very small amount of sample, but the patterns can only be observed for a very short time for an organic substance like cellulose due to radiation damage caused by the electron beam.

High resolution synchrotron $\mathrm{X}$-ray experiments have also been used to determine precise lattice parameters and the compositional ratio of cellulose $\mathrm{I} \alpha$ and $\mathrm{I} \beta$ in native cellulose from different sources including algae, bacteria, and plants (Wada et al., 1997). XRD peaks were deconvoluted using six types of profile functions such as Gaussian, Lorentzian, intermediate Lorentzian, modified Lorentzian, pseudo-Voigt, and Pearson VII. The pseudo-Voigt profile gave the best fit and was used to determine lattice spacings as shown in Table 1 . The relative content of cellulose I $\alpha$ was also determined based on the assumption that the first two equatorial reflections in the XRD pattern of Valonia cellulose are composites of cellulose I $\alpha$ (100) and cellulose I $\beta$ ( $1 \overline{1} 0)$, and of cellulose I $\alpha$ (110) and cellulose I $\beta$ (010) reflections. The two reflections were thus deconvoluted into four independent reflections using pseudo-voigt functions. The cellulose I $\alpha$ content $y_{\propto}$ was then estimated as:

$$
y_{\alpha}=\frac{J_{\mathrm{I}_{\alpha} 100}+J_{\mathrm{I}_{\alpha} 010}}{J_{\mathrm{I}_{\alpha} 100}+J_{\mathrm{I}_{\beta} 1 \overline{1} 0}+J_{\mathrm{I}_{\alpha} 010}+J_{\mathrm{I}_{\beta} 110}}
$$

where $J_{\text {IiXXX }}$ denotes the integrated intensities $J$ from I $\alpha$ and I $\beta$ reflections. The cellulose I $\alpha$ fraction was found to be 0.65 for Valonia cellulose, which was nearly equal to the value of 0.64 reported for Valonia cellulose from ${ }^{13} \mathrm{C}$ NMR (Yamamoto and Horn, 1994).

$\mathrm{X}$-ray diffraction is perhaps more widely used to study cell walls than other techniques because of multiple reasons, including less sensitivity of the sample to radiation damage, easier sample preparation, and easier data acquisition when compared to electron diffraction, and the ability to examine samples without the need of deuteration when compared to neutron diffraction. Nevertheless, because large single crystals of cellulose are not readily available, XRD studies are typically performed using protocols for powder diffraction, and the final results can depend on the model assumptions. Also, one of the limitations of diffraction techniques is that their results are averaged over space and time. These techniques cannot provide a dynamic visualization of the cellulose structure that is required to explain some of its properties. The complementary use of various spectroscopy techniques, such as NMR, IR, Raman and, more recently, neutron spectroscopy, have been beneficial to elucidating cellulose structure. A recent report on inelastic neutron scattering of cellulose explored the dynamics of hydrogen bond networks (Araujo et al., 2018). The effects of increasing water content in kraft cellulose was observed in the inelastic neutron scattering bands that are assigned to the hydroxymethyl group. Formation of ice microcrystals due to shock-freezing led to partial disruption of the hydrogen-bond network, which could be concluded from shifts of the $\mathrm{OH}$ vibrational mode observed in the spectra. 

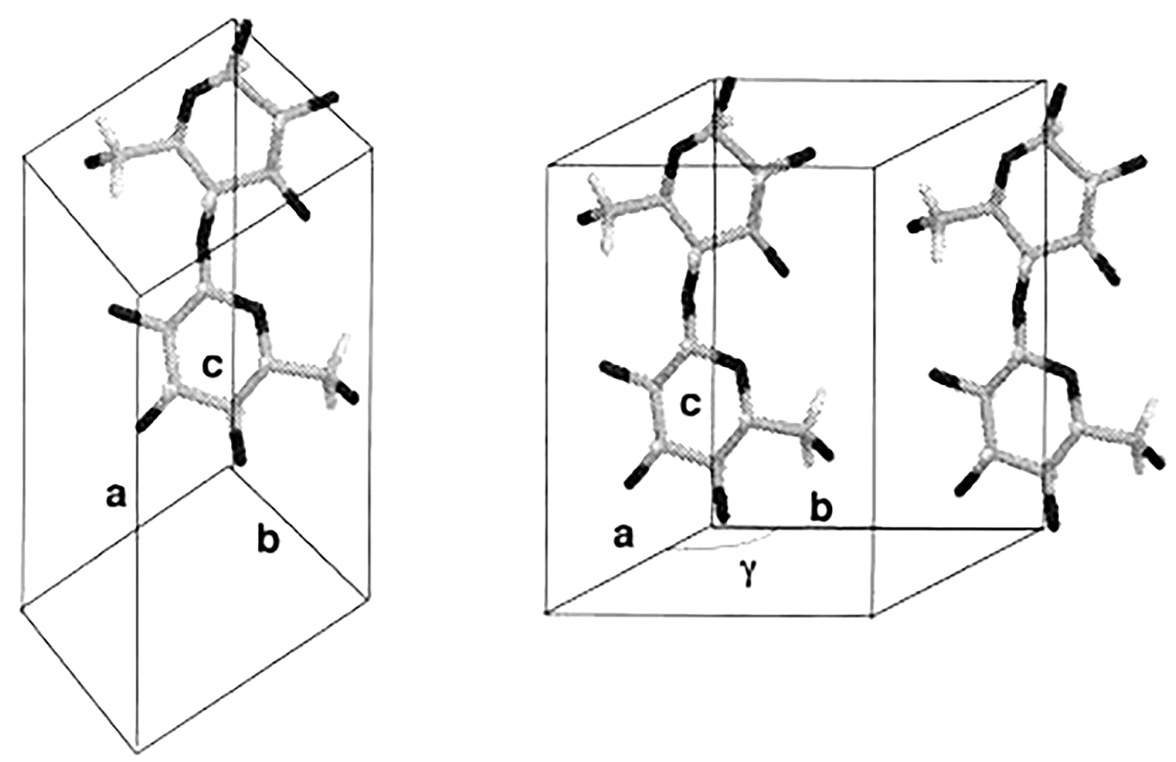

FIGURE 3 | Chain packing in unit cell of cellulose $\alpha \boldsymbol{\alpha}$ (left) and cellulose $\mid \beta$ (right). Reproduced from Koyama et al. (1997). Parallel-Up Structure Evidences the Molecular Directionality during Biosynthesis of Bacterial Cellulose PNAS 94 (17), 9091-9095. Copyright ( 1997 , The National Academy of Sciences of the United States.

TABLE $1 \mid d$-spacings of native cellulose calculated from synchrotron-based X-ray diffraction studies (Wada et al., 1997).

\begin{tabular}{lccc}
\hline & $\begin{array}{c}\boldsymbol{d}_{\mathbf{1}}, \mathrm{nm} \text { [composite } \\
\text { of triclinic (100) and } \\
\text { monoclinic (1 } \mathbf{1} \text { 0) } \\
\text { reflections] }\end{array}$ & $\begin{array}{c}\boldsymbol{d}_{\mathbf{2}}, \mathrm{nm} \text { [composite } \\
\text { monoclinic (110) } \\
\text { reflections] }\end{array}$ & $\begin{array}{c}\boldsymbol{d}_{\mathbf{3}}, \mathrm{nm} \text { [composite } \\
\text { of triclinic (110) and } \\
\text { monoclinic (200) } \\
\text { reflections] }\end{array}$ \\
\hline $\begin{array}{l}\text { Valonia } \\
\text { Cladophora }\end{array}$ & 0.610 & 0.531 & 0.392 \\
Chaetomorpha & 0.611 & 0.531 & 0.392 \\
Bacterial & 0.608 & 0.530 & 0.391 \\
cellulose & 0.614 & 0.530 & 0.394 \\
Halocynthia & 0.601 & 0.535 & 0.390 \\
Cotton & 0.601 & 0.536 & 0.393 \\
Ramie & 0.597 & 0.534 & 0.394 \\
Kouzo & 0.596 & 0.534 & 0.393 \\
\hline
\end{tabular}

\section{Identifying Allomorphs of Native Cellulose}

The early crystallographic data of native cellulose from different sources were inconsistent with each other with respect to chain packing (French et al., 1987), and the assumption of twofold screw symmetry ( $\mathrm{P}_{1}$ space group) was inconsistent with reflections observed in electron diffraction (Atalla, 1987). Additionally, the findings from applying new spectroscopic techniques to cellulose could not be rationalized on the basis of the then existing crystallographic models. The inconsistencies were resolved through solid state (SS) ${ }^{13} \mathrm{C}$ NMR spectral studies that led to the conclusion that native cellulose (cellulose I) is composed of two crystalline forms: cellulose $I \alpha$ and $I \beta$ (Atalla and Vanderhart, 1984). The two allomorphs are identified in plant cell walls, through spectroscopic and diffraction techniques as discussed in the following section. Figure $\mathbf{4}$ shows the XRD pattern and spectra obtained from NMR, SFG, IR, and Raman spectroscopy for different forms of cellulose. These techniques present spectra with distinct features for each of the allomorphs and can be used to estimate the relative contents of the forms of cellulose in a sample.

NMR spectroscopy provides qualitative and quantitative information about atoms in a sample and their chemical environments. The technique can distinguish between chemically equivalent carbons located at magnetically non-equivalent sites. The application of Cross-Polarization Magic Angle Spinning $(\mathrm{CP} / \mathrm{MAS}){ }^{13} \mathrm{C}$ NMR to study cellulose revealed that cellulose I $\alpha$ and $\mathrm{I} \beta$ can be differentiated in the NMR spectra based on the multiplicity of the C4 resonance peak near $88-90 \mathrm{ppm}$. Cellulose I $\alpha$ has a second peak in the down-field region while cellulose I $\beta$ has it in the up-field region. The relative abundance of the allomorphs is calculated by deconvolution of the resonance peaks in the C4 region (Yamamoto and Horii, 1993). Figure 4B shows the NMR spectra of cellulose $\mathrm{I} \beta$ in comparison to other forms of cellulose. Cellulose I, II, and III can be distinguished on the basis of the chemical shifts of the C6 resonance peak; they have signals at 65.5-66.2, 63.5-64.1, and 62.1-62.8 ppm, respectively (Isogai et al., 1989).

IR and Raman spectroscopy are vibrational spectroscopic techniques that can provide complementary information on chemical functionality, molecular conformation, and hydrogen bonding. IR spectroscopy requires a dipole change while Raman requires a polarizability change as a molecule rotates or vibrates. One key advantage of Raman over IR spectroscopy for the study of hydrated cell walls is that water appears as broad absorption bands in IR spectra, while water bands have weak 

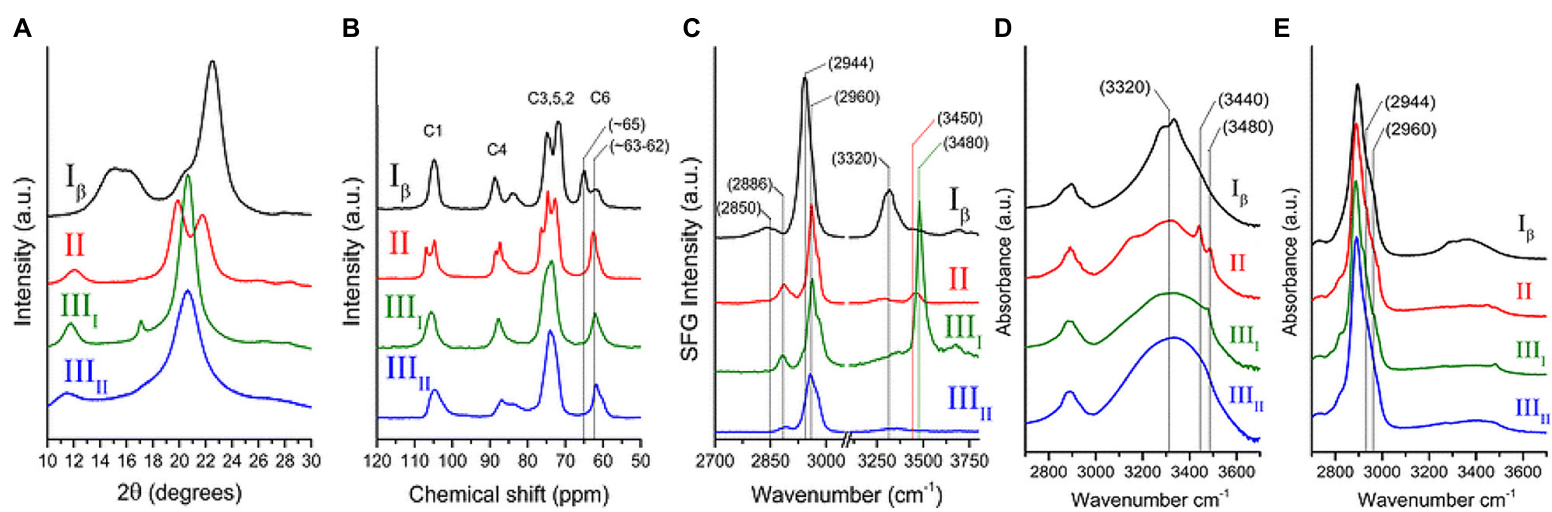

FIGURE 4 | Techniques used to characterize cellulose polymorphism: (A) XRD, (B) NMR, (C) SFG, (D) IR, and (E) Raman. Reprinted by permission from RightsLink Permissions: Springer Nature. Cellulose. Cellulose polymorphism study with sum-frequency-generation (SFG) vibration spectroscopy: identification of exocyclic $\mathrm{CH} 2 \mathrm{OH}$ conformation and chain orientation, Lee, C. M., Mittal, A., Barnette, A. L., Kafle, K., Park, Y. B., Shin, H., Johnson, D. K., Park, S., and Kim, S. H., Copyright (C) 2013.

intensities in Raman spectra. Moreover, changes in the refractive index of the material can cause variations in IR background but not in Raman, because excitation frequencies are far from absorption bands (Agarwal, 2014). When comparing the IR and Raman spectra of cellulose $\mathrm{I} \alpha$ and $\mathrm{I} \beta$, differences are observed in the $\mathrm{OH}$-stretching region (3200-3600 $\mathrm{cm}^{-1}$ ). In IR spectra, cellulose I $\alpha$ has peaks at 3240 and $750 \mathrm{~cm}^{-1}$ while cellulose I $\beta$ has peaks at 3270 and $710 \mathrm{~cm}^{-1}$ (Sugiyama et al., 1991a). These findings suggest that the two phases have similar chain conformations, but differ in hydrogen bonding patterns and dihedral angles at the glycosidic linkages. Line shape analyses of these characteristic peaks can be carried out to determine the mass fractions of cellulose $\mathrm{I} \alpha$ and $\mathrm{I} \beta$ in various cellulose samples (Yamamoto et al., 1996). Figures 4D,E compare the IR and Raman spectra of cellulose $\mathrm{I} \beta$ with the spectra obtained for cellulose II, $\mathrm{III}_{\mathrm{I}}$, and $\mathrm{III}_{\mathrm{II}}$. The main differences in the spectra are seen for the region above $3000 \mathrm{~cm}^{-1}$. Cellulose $\mathrm{I} \beta$ has a distinct peak at about $3320 \mathrm{~cm}^{-1}$, cellulose II has two peaks at about 3450 and $3480 \mathrm{~cm}^{-1}$, cellulose III I $_{\mathrm{I}}$ has one peak at about $3480 \mathrm{~cm}^{-1}$, while cellulose III II has no distinct sharp peak in this region.

Sum frequency generation (SFG) vibrational spectroscopy is a non-linear optical spectroscopy tool that is sensitive to non-centrosymmetric crystalline materials. As discussed in the Crystallinity of Cellulose, Spectroscopic Techniques Section, SFG is sensitive to structural ordering over an optical coherence length that enables it to characterize the structural hierarchy of cellulose microfibrils in the cell wall (Kim et al., 2013). NMR, IR, and Raman spectroscopy are widely used to study the conformation of purified cellulose, but their application is limited when it comes to native cellulose or lignocellulosic biomass, where spectral interference from other cell wall components cannot be avoided. The non-centrosymmetric requirement of SFG negates the interferences from SFG-inactive groups and thus enables the identification of exocyclic $\mathrm{CH}_{2} \mathrm{OH}$ conformation and chain orientation of forms of cellulose as shown in Figure 4C (Lee et al., 2013). Similar to IR and Raman spectroscopy, SFG also exhibits characteristic peaks for cellulose $\mathrm{I} \alpha$ at $3240 \mathrm{~cm}^{-1}$ and for cellulose I $\beta$ at $3270 \mathrm{~cm}^{-1}$ (Lee et al., 2015b).

\section{CRYSTALLINITY OF CELLULOSE}

Crystallinity is the ratio of crystalline to crystalline plus amorphous content by volume, and as such is a measure of structural order. Crystallinity affects mechanical properties such as strength and stiffness of cellulose and cellulose-derived materials. Higher cellulose crystallinity results in increased Young's modulus, tensile strength, density, and hardness (Lionetto et al., 2012). It is also an important parameter in many micromechanical models for wood (Bergander and Salmén, 2002; Hofstetter et al., 2005). Furthermore, the relative level of crystalline versus amorphous material within cellulose can influence the accessibility and reactivity of a given cellulose substrate to enzymes for biomass conversion. Given the importance of this metric, the crystallinity of cellulose has been estimated by many techniques, including XRD, IR and Raman spectroscopy, SS-NMR, SFG spectroscopy, Differential Scanning Calorimetry (DSC), and a variety of physicochemical assays. The measured crystallinity of cellulose can vary significantly depending on the technique and analysis approach used, with variations of up to $30-40 \%$ in reported values for cellulose-based materials (Thygesen et al., 2005; Park et al., 2010; Kljun et al., 2011; Agarwal et al., 2013; Karimi and Taherzadeh, 2016). Table 2 summarizes the crystallinity of cellulose derived from different sources as determined by XRD and NMR (Park et al., 2010). The lack of consensus reflects the challenges in measuring the degree of order in plant cell walls and the limitations of the aforementioned techniques, which we discuss below.

\section{Physicochemical Methods}

The Updegraff method is a commonly used chemical method for determining the amount of crystalline cellulose in a sample (Updegraff, 1969). This method 
TABLE 2 | Crystallinities of cellulose from different sources determined by XRD and NMR analysis methods.

\begin{tabular}{|c|c|c|c|c|}
\hline \multirow{2}{*}{$\begin{array}{l}\text { Cellulose } \\
\text { sample }\end{array}$} & \multicolumn{3}{|c|}{ XRD* } & \multirow{2}{*}{$\begin{array}{c}\text { NMR }^{* *} \\
\text { C4 peak } \\
\text { separation }\end{array}$} \\
\hline & $\begin{array}{c}\text { Peak } \\
\text { height }\end{array}$ & $\begin{array}{c}\text { Peak } \\
\text { deconvolution }\end{array}$ & $\begin{array}{l}\text { Amorphous } \\
\text { subtraction }\end{array}$ & \\
\hline $\begin{array}{l}\text { Bacterial } \\
\text { microcrystalline } \\
\text { cellulose }\end{array}$ & 95.2 & 73.1 & 82.4 & 73.8 \\
\hline Avicel PH-101 & 91.7 & 60.6 & 77.7 & 56.7 \\
\hline SigmaCell 50 & 91.2 & 61.3 & 79.4 & 56.1 \\
\hline SigmaCell 20 & 84.8 & 64.2 & 67.0 & 52.6 \\
\hline $\begin{array}{l}\text { JT Baker } \\
\text { cellulose }\end{array}$ & 85.5 & 61.5 & 69.1 & 49.1 \\
\hline Fluka cellulose & 82.9 & 52.9 & 61.6 & 48.6 \\
\hline $\begin{array}{l}\text { SolkaFloc } \\
\text { cellulose }\end{array}$ & 78.3 & 56.8 & 57.2 & 43.9 \\
\hline $\begin{array}{l}\text { Sigma } \\
\alpha \text {-cellulose }\end{array}$ & 78.0 & 55.9 & 54.4 & 41.5 \\
\hline
\end{tabular}

*XRD: X-ray Diffraction; **NMR: Nuclear Magnetic Resonance Spectroscopy. All values are means (Park et al., 2010).

involves extraction of lignin, hemicellulose, and xylosans with an acetic acid/nitric acid reagent, leaving behind crystalline cellulose. Cellulose is then dissolved in $67 \%$ $\mathrm{H}_{2} \mathrm{SO}_{4}$, and the amount of crystalline cellulose can be determined after treatment with an anthrone reagent to enable colorimetric analysis (Scott and Melvin, 1953; Kumar and Turner, 2015).

In principle, cellulose crystallinity should be related to accessibility. The moisture sorption of cellulose takes place primarily by hydrogen bonding of water to accessible hydroxyls in less ordered regions at the surfaces of elementary fibrils and their random fibrillar aggregations at relative humidities lower than $50-60 \%$. Thus, moisture regain of cellulose is a more direct measure of cellulose accessibility to reactants, rather than crystallinity. It is common practice to relate accessibility to crystallinity through the following equation (Howsmon, 1949):

$$
A=\sigma X+(100-X)
$$

where $A$ is the percentage of accessible cellulose in the sample, $\sigma$ is the fraction of accessible cellulose on the surface of crystalline regions, and $X$ is the percentage of crystalline cellulose in the sample.

The determination of accessibility of glucan chains based on deuterium exchange is based on the assumption that accessible $\mathrm{OH}$ groups in amorphous regions of cellulose readily exchange their hydrogen atoms for deuterium while the $\mathrm{OH}$ groups in crystalline regions exchange more slowly. Accordingly, the reaction curve for exchange reactions has two separate regions: an initial rapid rate region followed by a slow rate regime (Frilette et al., 1948), and the crystallinity has been related to accessibility similarly as shown in equation 2 .

Because iodine is reported to be adsorbed in the amorphous regions of cellulose, measurements of iodine adsorption have also been used to determine crystallinity (Hessler and Power, 1954). The amount of iodine adsorption per gram of cellulose has been linked to the fraction of amorphous cellulose within a sample. The crystallinity was then estimated by subtracting the amorphous fraction from 100.

A recent report has attempted to calculate the absolute degree of crystallinity of cellulose based on sorption of water vapor and enthalpy of wetting (Ioelovich, 2016). The crystallinity $x$ of cellulose is calculated from sorption of water using the following equation that is derived from the sigmoidal isotherm of sorption of water vapor by semi-crystalline cellulose:

$$
x=1-2 A(1-2.61 \ln \varphi)
$$

where $A$ is the relative amount of water in cellulose by mass and $\varphi$ is the relative vapor pressure at a constant temperature of $25^{\circ} \mathrm{C}$. Under the assumption that water molecules interact with amorphous domains of cellulose and this interaction is accompanied by release of heat, the enthalpy of wetting is directly proportional to the amount of amorphous cellulose content. Then the crystallinity can also be determined by:

$$
x=1-\frac{\Delta H}{\Delta H_{\mathrm{am}}}
$$

where $\Delta H_{\mathrm{am}}$ is the enthalpy of wetting of purely amorphous cellulose. A value of $\Delta H_{\mathrm{am}}=-167.5 \mathrm{~J} / \mathrm{g}$ has been reported and used to estimate crystallinity (Ioelovich, 2016). The crystallinity of microcrystalline cellulose samples was found to range from 0.72 to 0.75 , as determined from the enthalpy of wetting and water sorption methods.

When compared to the crystallinity found from XRD measurements, physicochemical methods typically report a higher value of crystallinity. One possible origin of the discrepancy is the compositional and structural heterogeneity of cell walls, in particular of primary cell walls, that might complicate access to non-crystalline components. This would invalidate the assumption of a direct relationship between crystallinity and the physical and chemical properties investigated by these methods.

\section{X-Ray Diffraction}

$\mathrm{X}$-ray diffraction is the most widely used technique for determining the crystallinity of cellulose due to its established reliability and accuracy, and minimal sample preparation requirements. XRD gives a measure of crystallinity as the mass fraction of crystalline cellulose within the entire sample (Ahvenainen et al., 2016). As shown in Figure 5, three methods are widely used for estimation of crystallinity from XRD, including: (i) the peak height or Segal method; (ii) peak deconvolution of crystalline and amorphous peaks; and (iii) the amorphous subtraction or RulandVonk method. These approaches are discussed extensively in various reviews (Park et al., 2010; Kim et al., 2013; Ju et al., 2015; Karimi and Taherzadeh, 2016) and are described briefly below.

The peak height method, also called the Segal method (Segal et al., 1959), is the most widely used analysis approach 


\section{- = Fit - Measurement - - -Amorphous component - Crystalline component}
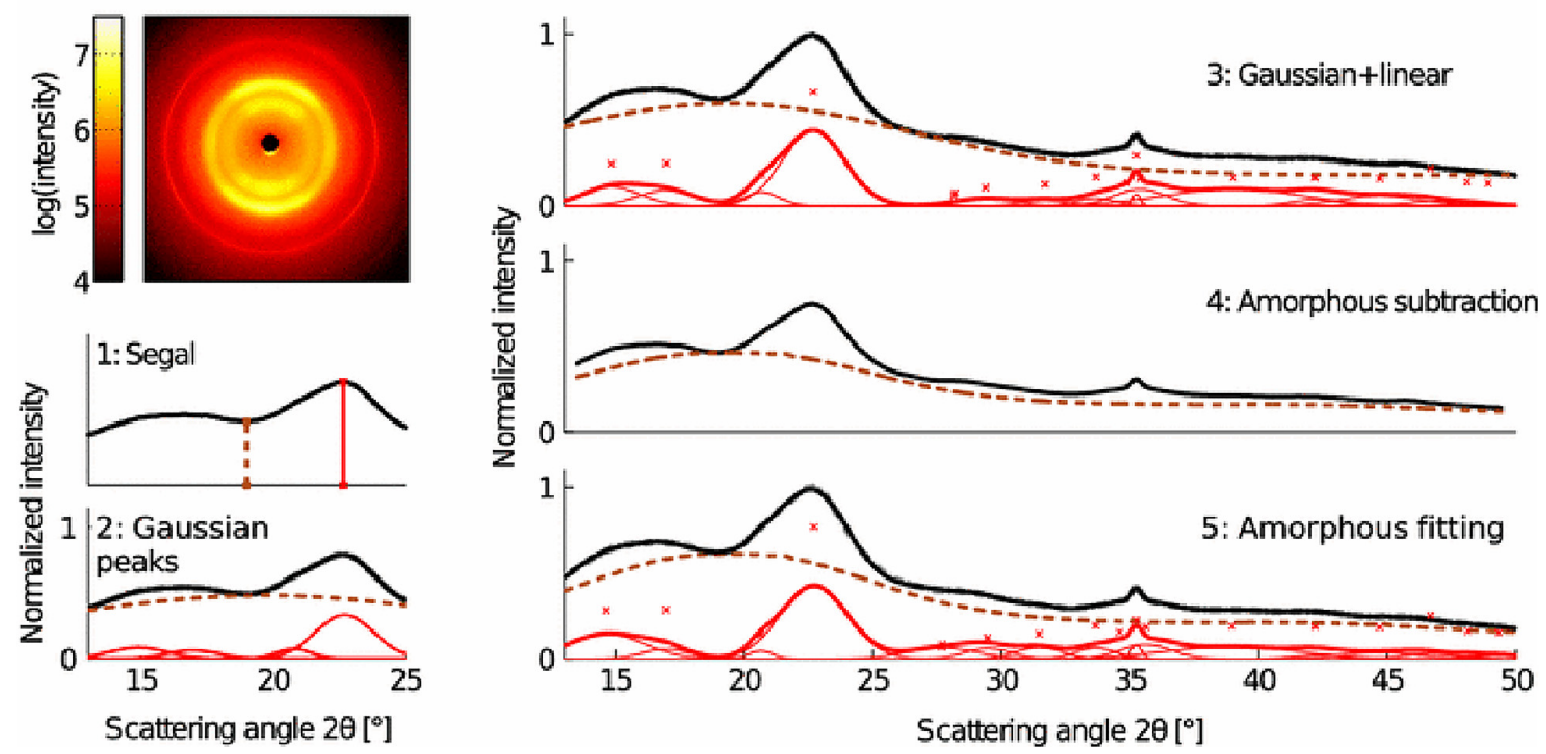

FIGURE 5 |X-ray diffraction methods for determination of the crystallinity of cellulose. Reprinted by permission from RightsLink Permissions: Springer Nature. Cellulose. Comparison of sample crystallinity determination methods by X-ray diffraction for challenging cellulose I materials, Ahvenainen, P., Kontro, I., and Svedström, K., Copyright $\odot 2016$.

to characterize the crystallinity of cellulosic samples. The crystallinity $x$ is calculated by:

$$
x=\frac{I_{200}-I_{\mathrm{AM}}}{I_{200}}
$$

where $I_{200}$ is the height of the (200) peak and $I_{\mathrm{AM}}$ is the height of the minimum between the (200) and (110) peaks. This method is not very accurate as the exact amount of the crystalline fraction is proportional to the peak area rather than to the peak height. Also, the underlying assumption of equation 5 is that scattering intensities from amorphous and crystalline content are equivalent per unit volume, which actually depends on the details of the structure factor of each of these phases. As a consequence, the crystallinity obtained using this method is dependent on crystallite size and cellulose allomorph (Ju et al., 2015).

The second method is based on peak deconvolution of crystalline and amorphous peaks. In XRD data, crystalline cellulose is represented by several intense peaks at (110), (102), (200), and (004) for cellulose I $\beta$ and a single broad peak for the amorphous phase. Gaussian, Lorentzian, and Voigt functions are commonly used for peak fitting and the ratio of the area of the crystalline peaks to the total area is defined as the crystallinity. The accuracy of this method depends on selecting the correct peaks that correspond to the actual diffraction contributed by each fraction.

In the third method, also called the amorphous subtraction or Ruland-Vonk method (Ruland, 1961), the crystallinity is defined as the ratio of an area above an amorphous profile to the total area. The amorphous profile is obtained either from a polynomial function or a pattern measured from experimentally prepared material believed to be entirely amorphous, such as ballmilled cellulose, regenerated cellulose, xylan, or lignin powder. In this method, a scaling factor is applied to the amorphous spectrum so that after subtraction from the original spectrum, no negative signal occurs in the residual spectrum. Often, the scaled amorphous background touches the diffractogram somewhere in the low $q$ (low 20) region where the intensity is most poorly determined due to the fine adjustment of slits and the effects of axial divergence, so the method is sensitive to instrumental inaccuracies. It can also be difficult to compare samples of different origin. In addition, it can be challenging to compare results from different studies due to the variability in the amorphous standard used.

The crystallinity obtained from XRD can depend on crystallite size and preferred orientation of crystallites. The use of areabased fitting methods can better avoid the effects of crystallite size than peak height-based methods. The effects of preferred orientations can be mitigated by use of 2D Rietveld refinement, which includes the contribution of all diffraction peaks and two-dimensional diffraction data. Both $1 \mathrm{D}$ and 2D Rietveld refinement of XRD data are reported to accurately determine the degree of crystallinity (Thygesen et al., 2005; De Figueiredo and Ferreira, 2014; Driemeier, 2014). Because 2D Rietveld analysis is done on $2 \mathrm{D}$ diffraction data, it takes into account the preferred orientation and thus is considered more accurate for textured samples (Ahvenainen et al., 2016).

Additional approaches to estimate the crystallinity of cellulose from XRD data have also been developed, including the Hermans-Weidinger method (Gusev, 1978) and the Debye method (Thygesen et al., 2005), although these approaches 
are less widely used in comparison to the abovementioned analyses. The Hermans-Weidinger method was developed for the determination of polymer crystallinity based on the proportionality of X-ray scattering intensities of crystalline and amorphous parts of a polymer. The proportionality is expressed as:

$$
\frac{x_{1}}{x_{2}}=\frac{I_{c_{1}}}{I_{c_{2}}}
$$

where $x_{\mathrm{I}}$ is the degree of crystallinity and $I_{c \mathrm{I}}$ is the scattering intensity from the crystalline region. Crystallinity of a sample (labeled 1 in equation 6) can be determined only when a sample of known crystallinity (labeled 2) is available. The Debye method is similar to the Rietveld refinement method with the difference being that it requires simulation and fitting of the diffractogram to the experimental data to determine the quality of the fit (Thygesen et al., 2005). This approach has an advantage over the Rietveld method as the crystallite dimensions are included explicitly in the simulations and not fitted by analytical peak profile functions. This enables the Debye method to give the most reliable estimate of the crystalline part of the diffraction pattern, but it is less commonly used due to the heavy computing efforts required.

A robust estimate of the crystallinity from XRD measurements requires consideration of various approaches for data analysis. Even then, the limitations highlighted above preclude confidence in absolute values, although relative values for the crystallinity can reveal trends in samples that differ minimally (e.g., within the same species). Often, the term "crystallinity index" is used for crystallinities obtained from XRD to emphasize the challenges with comparing these values to those extracted from other techniques.

\section{Spectroscopic Techniques}

The intra- and inter-molecular hydrogen bonds found in crystalline cellulose can be analyzed using IR spectroscopy. The absorption band between 1420 and $1430 \mathrm{~cm}^{-1}\left(A_{1430}\right)$ is assigned to a symmetric $\mathrm{CH}_{2}$ bending vibration, known as the "crystallinity band," and the band appearing between 893 and $898 \mathrm{~cm}^{-1}\left(A_{898}\right)$ is assigned to $\mathrm{C}-\mathrm{O}-\mathrm{C}$ stretching at $\beta$ - $(1 \rightarrow 4)$-glycosidic linkages, known as the "amorphous band" (Nelson and O'Connor, 1964). Two terms related to crystallinity of cellulose have been defined, namely Lateral Order Index (LOI) and Total Crystallinity Index (TCI). LOI, also called the empirical crystallinity index, is the ratio of the intensities of $A_{1430}$ to $A_{898}$ and is sensitive to the amount of crystalline versus amorphous regions in cellulose. A lower LOI indicates a more amorphous structure (O'Connor et al., 1958). TCI is the ratio of the absorption band at 1372 to 2900 (Nelson and O'Connor, 1964; Poletto et al., 2014). The band at $1372 \mathrm{~cm}^{-1}$ is assigned to $\mathrm{C}-\mathrm{H}$ bending and is reported to be affected by the amorphous content of a cellulose sample while the band at $2900 \mathrm{~cm}^{-1}$ is assigned to $\mathrm{C}-\mathrm{H}$ and $\mathrm{CH}_{2}$ stretching and is reported to be unaffected by changes in crystallinity. Taking the ratio of intensities of these bands as TCI enables the crystallinity index to be insensitive to sources of variation other than changes in crystallinity. IR spectroscopy is routinely used to characterize woody biomass meant for biofuel conversion (Amiri and Karimi, 2015; Noori and Karimi, 2016).

Different peak ratios in Raman spectra have been reported in literature as a measure of crystallinity. The relative intensity ratios of the Raman bands 1481 and $1462 \mathrm{~cm}^{-1}$ in cellulose I (Schenzel et al., 2005) and that of 380 and $1096 \mathrm{~cm}^{-1}$ bands (Agarwal et al., 2010) are both reported as measures of the crystallinity. Unfortunately, both IR and Raman spectroscopy face challenges when characterizing the crystallinity present in primary cell walls due to the interference of signals from other wall components.

In the ${ }^{13} \mathrm{C}$ NMR spectra of cellulose, the peak at $89 \mathrm{ppm}$ is assigned to $\mathrm{C} 4$ in crystalline cellulose and the peak at $84 \mathrm{ppm}$ to amorphous cellulose (Atalla and VanderHart, 1999). The crystallinity from NMR spectra is defined as the integral area of the C4 peak from 87 to $93 \mathrm{ppm}$ divided by the total integral area assigned to the $\mathrm{C} 4$ peaks (from 80 to $93 \mathrm{ppm}$ ). This method has been used to determine the degree of crystallinity in wood (Newman and Hemmingson, 1990; Newman et al., 1993) and to study the effect of crystallinity on enzymatic degradation of cellulose (Mansfield and Meder, 2003). It has also been applied to estimate crystallinity in primary cell walls of cellulose synthase mutants of Arabidopsis thaliana (Harris et al., 2012).

As introduced earlier, the non-centrosymmetric requirement of SFG allows selective detection of cellulose in plant cell walls and characterization of its structural properties. SFG has also been used to determine the amount of crystalline cellulose in secondary cell wall samples, which was estimated by applying a calibration curve from Avicel to the intensity of the $\mathrm{CH}_{2}$ SFG peak of cellulose at $2945 \mathrm{~cm}^{-1}$ (Barnette et al., 2012). The limitations of this technique lie in the assumption of $100 \%$ crystalline Avicel, the assumption of the same signals from Avicel cellulose and from the biological systems under study, and the neglect of the effect of crystal size. Perhaps as a consequence, the technique has not yet been reported for crystallinity studies of primary cell walls.

\section{CELLULOSE MICROFIBRIL SIZE AND ORGANIZATION}

Direct visualization of the cell wall through light microscopy shows the existence of cellulose in a bundled fibrillar structure. High resolution electron microscopy reveals microfibrils that are aggregated, such that individual microfibrils (sometimes termed elementary fibrils) have cross-sections of 2-4 $\mathrm{nm}$ and lengths of $100 \mathrm{~nm}$ or more (Kraissig, 1992). Complete understanding of this fibrillar network requires the characterization of structural parameters, including fibril length, lateral size and shape, as well as the spatial arrangement of microfibrils. These parameters have a strong influence on the mechanical and physicochemical properties of cellulose and its derivatives. The following section discusses the characterization of the abovementioned parameters through different techniques such as microscopy, diffraction/scattering, spectroscopy, and chemical methods. We cover examples from studies of bacterial cellulose, primary cell walls, and secondary cell walls. 


\section{Size and Shape of Cellulose Microfibrils}

Perhaps the simplest approach to estimate the dimensions of microfibrils relies on physicochemical methods. Under the assumption that the microfibril length is equal to the chain length, the length is estimated from the degree of polymerization (DP) of residual cellulose that remains after an initial drastic drop upon dissolution in dilute acid. This degree of polymerization is called the leveling off DP, and the crystallite length is estimated as the product of the leveling off DP and length of one monomer unit. The DP of cellulose has also been determined through light scattering, osmotic pressure, and gel permeation chromatography (Levi and Sellen, 1967; Holt et al., 1973). The crystallite width is calculated by observing the reactivity of cellulose toward dilute mineral acid and deuterium oxide. Under the hypothesis that both acid hydrolysis and deuteration take place in the amorphous regions, but only deuteration takes place on the surface, the number of molecules per side of a rectangular cross-section is calculated and multiplied by the

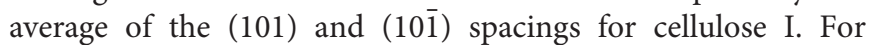
example, values for the crystallite width are $31 \AA$ for cotton and $33 \AA$ for Ramie, with crystallite lengths of about $100 \mathrm{~nm}$ for both (Scallan, 1971). As discussed below, these crystallite widths are consistent with measurements from electron microscopy and other techniques.

Various approaches have attempted to directly image the size and shape of microfibrils (Table 3). The use of electron microscopy along with techniques like metal shadowing (Bayley et al., 1957; Beer and Setterfield, 1958), negative staining (Heyn, 1966; Revol, 1982; Manley, 2003), and diffraction contrast imaging (Bourret et al., 1972; Revol, 1982) have revealed valuable structural information about cellulose from several sources including valonia, jute, cotton, and ramie fibers. Based on the findings from X-ray diffraction/scattering and electron microscopy of cellulose materials following different chemical treatments, two descriptions of microfibrils developed. One hypothesis stated that each microfibril has a single crystalline core whose size is almost the same as a microfibril, while an alternative hypothesis stated that each microfibril was composed of elementary microfibrils of $35 \AA$ width (Nieduszynski and Preston, 1970). The former hypothesis was supported with studies on bacterial cellulose, where apparent crystallite lateral dimensions are much larger than $35 \AA$, and not necessarily in its multiples. Cellulose crystallites from Chaetomorpha melagonium and Acetobacter xylinum were found to measure between 100 and $200 \AA$ when studied through X-ray diffraction and electron microscopy (Colvin, 1963; Nieduszynski and Preston, 1970). Further work based on high resolution imaging techniques was crucial to resolve these conflicting descriptions of cellulose organization, as described below.

Lattice imaging of native cellulose from ramie fibers and different algal and bacterial sources was made possible with high resolution electron microscopy in combination with negative staining, metal shadowing, and diffraction contrast imaging (Sugiyama et al., 1985; Kuga and Brown, 1987a,b). These studies established that each microfibril corresponds to a single crystalline entity. Negative staining of sections of cellulose from cotton, ramie, and jute fibers revealed lateral dimensions between
TABLE 3 | Microfibril diameter from different sources of cellulose obtained through the use of different analytical characterization techniques.

\begin{tabular}{|c|c|c|}
\hline Source of cellulose & $\begin{array}{c}\text { Microfibril } \\
\text { diameter }(\mathrm{nm})\end{array}$ & Techniques* \\
\hline Arabidopsis thaliana & $5.8 \pm 0.17$ & AFM (Davies and Harris, 2003) \\
\hline \multirow[t]{3}{*}{ Celery collenchyma } & 2.4-3.6 & $\begin{array}{l}\text { NMR, SAXS, WAXS (Kennedy } \\
\text { et al., 2007a) }\end{array}$ \\
\hline & $2.9-3.0$ & $\begin{array}{l}\text { SANS, WAXS (Thomas et al., } \\
\text { 2013) }\end{array}$ \\
\hline & $2.6-3.0$ & SAXS (Kennedy et al., 2007b) \\
\hline Celery parenchyma & $6.0-25.0$ & AFM (Thimm et al., 2000) \\
\hline \multirow[t]{3}{*}{ Cotton } & $2.5-4.0$ & TEM (Heyn, 1966) \\
\hline & $4.9-6.1$ & $\begin{array}{l}\text { TEM (Nieduszynski and } \\
\text { Preston, 1970) }\end{array}$ \\
\hline & 5.5 & SAXS (Heyn, 1955) \\
\hline \multirow[t]{2}{*}{ Flax fiberes } & $1.0-5.0$ & $\begin{array}{l}\text { SAXS (Astley and Donald, } \\
\text { 2001) }\end{array}$ \\
\hline & 2.8 & SAXS (Heyn, 1955) \\
\hline \multirow[t]{2}{*}{ Jute } & 2.8 & TEM (Heyn, 1966) \\
\hline & 2.8 & SAXS (Heyn, 1955) \\
\hline \multirow[t]{2}{*}{ Maize } & $3.2-5.3$ & AFM (Ding and Himmel, 2006) \\
\hline & $2.5-3.5$ & $\begin{array}{l}\text { WAXS, NMR (Rondeau-Mouro } \\
\text { et al., 2003) }\end{array}$ \\
\hline Mung bean & $2.5-3.2$ & $\begin{array}{l}\text { WAXS, NMR (Newman et al., } \\
\text { 2013) }\end{array}$ \\
\hline Oak wood & $2.9-3.1$ & $\begin{array}{l}\text { WAXS, SAXS (Svedström et al., } \\
\text { 2012) }\end{array}$ \\
\hline \multirow[t]{2}{*}{ Onion } & $8.0-10.0$ & NMR (Ha et al., 1998) \\
\hline & $4.4 \pm 0.13$ & AFM (Davies and Harris, 2003) \\
\hline Quince & 2.0 & NMR (Ha et al., 1998) \\
\hline \multirow[t]{3}{*}{ Ramie } & $3.6-4.8$ & TEM (Heyn, 1966) \\
\hline & 5.9 & $\begin{array}{l}\text { TEM (Nieduszynski and } \\
\text { Preston, 1970) }\end{array}$ \\
\hline & 4.3 & SAXS (Heyn, 1955) \\
\hline \multirow[t]{4}{*}{ Spruce wood } & 2.5 & $\begin{array}{l}\text { TEM, WAXS, SAXS (Jakob } \\
\text { et al., 1995) }\end{array}$ \\
\hline & 2.9 & WAXS (Andersson et al., 2000) \\
\hline & $3.1-3.2$ & $\begin{array}{l}\text { SANS, WAXS (Fernandes et al., } \\
\text { 2011) }\end{array}$ \\
\hline & $2.9-3.1$ & WAXS (Peura et al., 2007) \\
\hline Sugi wood & $2.4-2.6$ & $\begin{array}{l}\text { SAXS (Suzuki and Kamiyama, } \\
\text { 2004) }\end{array}$ \\
\hline Tunicin & $3.4-7.6$ & $\begin{array}{l}\text { TEM (Nieduszynski and } \\
\text { Preston, 1970) }\end{array}$ \\
\hline \multirow[t]{3}{*}{ Valonia ventricosa } & 18.0 & TEM (Revol, 1982) \\
\hline & $10.0-20.0$ & WAXS (Caulfield, 1971) \\
\hline & 3.0 & $\begin{array}{l}\text { WAXS, NMR, IR (Horikawa } \\
\text { et al., 2009) }\end{array}$ \\
\hline
\end{tabular}

*AFM, atomic force microscopy; NMR, nuclear magnetic resonance spectroscopy; SAXS, small angle $X$-ray scattering; SANS, small angle neutron scattering; WAXS, wide angle $X$-ray scattering (synonymous with $X R D$ ); TEM, transmission electron microscopy, IR, infrared spectroscopy.

25 and $40 \AA$ (Heyn, 1966). As shown in Figure 6, transmission electron microscopy (TEM) with negative staining has also been used to demonstrate individual cellulose microfibrils that result from various alkaline treatments of vascular bundles of banana rachis (Zuluaga et al., 2009). Using electron diffraction and dark field electron microscopy, cellulose crystallites from 


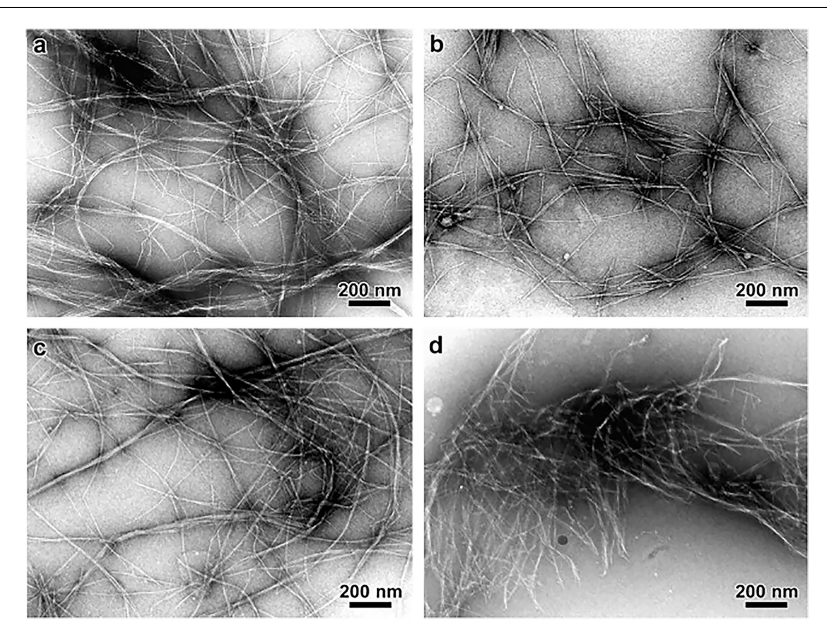

FIGURE 6 | Transmission Electron Microscopy micrographs comparing the morphology of cellulose microfibrils isolated by different chemical treatments. (a) Peroxide alkaline, (b) peroxide-alkaline-hydrochloric acid, (c) 5 wt\% potassium hydroxide, and (d) $18 \mathrm{wt} \%$ potassium hydroxide. The combination of peroxide alkaline and hydrochloric acid or the application of a high concentration (18wt\%) potassium hydroxide solution leads to shorter microfibrils, suggesting these treatments can cause microfibril scission. Reprinted from Carbohydrate Polymers, 76, Zuluaga, R., Putaux, J. L., Cruz, J., Vélez, J., Mondragon, I., Gañán, P. Cellulose microfibrils from banana rachis: Effect of alkaline treatments on structural and morphological features, 51-59, Copyright (C) 2009, with permission from Elsevier.

algae (Valonia ventricosa) were found to be above $1000 \AA$ in length and 140 to $180 \AA$ in width (Bourret et al., 1972). Thus, although the "elementary" unit appears to be a microfibril of a few nanometers, dimensions of cellulose crystallites appear to vary depending on the source. In a similar way, no agreement has been reached on the cross-sectional shape of cellulose found from imaging. The cross-section of valonia microfibrils was found to be almost square-shaped with an average size of 180-200 A (Revol, 1982; Sugiyama et al., 1985) while the cross-section of tunicate cellulose was found to be parallelogram shaped (Helbert et al., 1998a,b). Even though valuable information has been obtained about cellulose microfibrils from electron microscopy, the sample preparation that generally requires drying could introduce artifacts through modifications in the physical structure of native cellulose, such as collapse and aggregation of microfibrils. This has limited the study of microfibril shape and diameter in primary cell walls through TEM.

As an alternative to electron microscopy, scanning force microscopy (SFM), also termed atomic force microscopy (AFM), and optical microscopy are techniques that can visualize cellulose microfibrils with spatial resolution ranging from the micrometer to the sub-nanometer scale in biologically relevant environments. AFM techniques reveal the surface topology by measuring the interaction between a fine physical probe and the surface of the sample. Imaging contrast is based on variations of the sample topology, modulus, or interaction with the probe. AFM can record the surface topography and properties at the nanoscale by scanning a sample under a sharp stylus or tip, which is often made from silicon or silicon nitride. The stylus is attached to a cantilever, which is deflected as the stylus interacts with the surface. Images are produced by measuring the deflection of the cantilever as the sample is scanned. Alternatively, atomic force microscopes can be operated in constant-force mode in which a feedback system is used to keep the deflection constant (Prater et al., 1990). AFM enables direct characterization of sample surfaces with high spatial resolution (0.1-100 nm) and minimal sample preparation; thus, AFM is ideal for characterizing the structure of cell walls, as many features can be detected within this resolution range (Yarbrough et al., 2009). Samples need not be fixed, stained, dried, or metal coated as in the case of electron microscopy. Even if a pectin layer is present, the tip can probe through this soft layer to reveal the microfibril structure underneath in primary cell walls (Zhang et al., 2014, 2016).

The earliest cellulose-containing biological samples studied using AFM were dried cells of archae-bacterium Halobacterium halobium (Butt et al., 1990); later studies focused on bacterial polysaccharides (Gunning et al., 1995) and cellulose from root hair cell wall of Zea mays and Raphanus sativus (van der Wel et al., 1996). AFM has also been used to visualize cellulose microfibrils in hydrated primary cell walls from apple, water chestnut, potato, and carrot (Kirby et al., 1996). These measurements supported the polylaminate description of cell wall structure. Furthermore, the effect of hydration on the diameter of cellulose microfibrils in celery parenchymal cell walls was studied using AFM. It was found that the measured diameters depend on the water content of the samples and also on the procedure of dehydration, with diameters ranging from $15.2 \pm 0.4 \mathrm{~nm}$ before dehydration to $25.1 \pm 0.8 \mathrm{~nm}$ after dehydration (Thimm et al., 2000). Nevertheless, as the tip scans across the surface, it can lead to broadening of lateral features due to the width of the tip itself, leading to differences in measured microfibril diameters from AFM in comparison to other techniques. Measuring the height of microfibrils (in the $\mathrm{z}$-direction) resolves this problem, as was done to find the dimensions of cellulose microfibrils from partially hydrated cell walls of onions and A. thaliana (Davies and Harris, 2003). Microfibrils were $4-6 \mathrm{~nm}$ in diameter and contain a single cellulose crystallite, $2-3 \mathrm{~nm}$ wide, which is surrounded by noncellulosic polysaccharides. It was also found that removal of pectin from the cell wall improved the accuracy of measurements. AFM studies of maize parenchyma cell wall indicated microfibril dimensions similar to that found in onion and A. thaliana as discussed above, although the authors proposed a 36-chain model for each microfibril (Ding and Himmel, 2006). AFM has also been used to compare cellulose microfibrils in different scales of onion (Kafle et al., 2014; Tittmann and Xi, 2014; Zhang et al., 2014). These studies showed that the microfibrils are more ordered in older scales than in younger scales. Altogether, previous work has demonstrated AFM as a powerful tool for imaging of the cell wall in physiological environments.

Scanning Electron Microscopy (SEM) is an alternative approach to image the surface of plant cell walls. Sample preparation for SEM is simpler than for TEM, because electron-transparent samples and heavy metal staining are not required. SEM allows imaging cell walls directly and has been used to observe the cell wall structure of both primary (Crow 
and Murphy, 2000; Carpita et al., 2001) and secondary cell walls (Awano et al., 2002; Kim et al., 2012). Measurements of microfibril dimensions are consistent with estimates derived from AFM (Zheng et al., 2018). Nevertheless, SEM usually requires dehydration or critical-point drying, removal of the top pectin layer (if present), as well as deposition of a conductive coating to prevent charging, which may cause artifacts. As a consequence, the technique is often used to complement other microscopic and spectroscopic techniques. For example, SEM has been used along with IR spectroscopy to study the cell wall architecture of Maize coleoptile (Carpita et al., 2001), and with AFM to study different plant tissues like cucumber hypocotyls, A. thaliana, and onions (Marga et al., 2005; Xiao and Anderson, 2016; Zhang et al., 2016).

In addition to estimates from real-space images, estimates of microfibril dimensions have been obtained from reciprocal space techniques. These approaches have the advantage of averaging structural features over large areas. Line broadening in X-ray diffraction (XRD, or wide-angle X-ray scattering, WAXS) is directly related to the coherence length $t$, as given by the Scherrer formula:

$$
t=\frac{k \lambda}{\beta \cos \theta}
$$

where $\lambda$ is the $\mathrm{X}$-ray wavelength, $\theta$ is the Bragg angle, $k$ is a shape factor that is often 0.89 , and $\beta$ is the angular half width of the line profile. The coherence length is equivalent to the crystal size if fluctuations or defects in the crystal lattice are not cumulative, such that deviations from ideal average lattice positions do not disrupt the long-range order of the lattice. Under this assumption, early applications of this approach measured the cellulose crystallite size for valonia, tunicin, cotton, ramie, Acetobacter xylinum, and Chaetomorpha melagonium (Nieduszynski and Preston, 1970; Caulfield, 1971). Line broadening of the equatorial reflections (200) and (110/110) give the lateral dimension while the meridional reflection (004) gives the longitudinal dimension. The reported crystal widths from XRD (100-200 ̊) significantly exceed values reported for microfibril diameters from electron microscopy (35 ̊) and other techniques (see Table 3). One possible explanation is that microfibrils aggregate and strong interactions maintain lattice coherence, thereby leading to apparent larger crystal dimensions from X-ray experiments.

Analyses of XRD data have also attempted to resolve diffraction peaks into Gaussian and Cauchy profiles (Hindeleh and Johnson, 1972, 1974). The obtained crystallite sizes did not support the existence of elementary microfibrils. The results, however, depend a lot on the details of the model adopted for peak fitting, such as the type of fitting function and background subtraction. Other factors like crystal morphology, distortions, and size distribution also affect the results.

In addition to X-ray diffraction, small-angle scattering techniques have also been employed to examine the dimensions of microfibrils. These techniques involve analysis of the intensity of radiation scattered from the sample as a function of the scattering vector $q$. Focusing on small scattering angles can reveal the size and shape of objects, such as the diameter of rod-like microfibrils. Diameters of highly oriented fibrils were obtained from Small Angle X-ray Scattering (SAXS) of ramie, cotton, jute, flax, and cordura using Guinier plots for cylindrical particles (Heyn, 1955). The sizes obtained for jute, ramie, and cotton were in agreement with coherence lengths (crystal sizes) previously obtained from XRD and with diameters obtained from electron microscopy with negative staining (Heyn, 1966). Nevertheless, the weak spatial organization of primary cell walls make interpretation of SAXS profiles challenging; yet, SAXS has successfully been used to examine the size and arrangement of cellulose fibrils in secondary cell walls of spruce wood (Picea abies). An almost constant diameter of $2.5 \mathrm{~nm}$ with a standard deviation as small as $0.14 \mathrm{~nm}$ was found for measurements from 10 different trees (Jakob et al., 1994). This microfibril diameter was in good agreement with that obtained from TEM, which reported the diameter to be $2.4 \mathrm{~nm}$ but with a standard deviation as high as $1.3 \mathrm{~nm}$. Other work has demonstrated good agreement between SAXS profiles and Fourier transforms of TEM micrographs (Jakob et al., 1995).

An advantage of SAXS is the ability to perform experiments under moist environments; for example, hydration-dependent structural changes of cellulose microfibrils in spruce wood have been examined (Jakob et al., 1996). The packing density and fibril center-to-center distance was estimated, and it was found that the structure of the cell wall was independent of hydration if the moisture content was above the saturation point of fibrils. Comparable measurements were not possible for moisture content below the saturation point, as the scattering from pores could not be neglected. Similarly, SAXS has been used to study the effect of hydration on cellulose from different sources including Acetobacter xylinus, flax, sugi wood, and celery collenchyma (Astley and Donald, 2001; Astley et al., 2001; Suzuki and Kamiyama, 2004; Kennedy et al., 2007b). Such studies are mostly on secondary cell walls as in the case of flax or wood. Celery collenchyma offers a convenient experimental platform for studying hydrated primary cell walls through scattering as they have unusually well oriented microfibrils. It has been reported that hydration increases the mean microfibril spacing from $3.8 \mathrm{~nm}$ in dry cell walls to $5.4 \mathrm{~nm}$ in hydrated cell walls of celery collenchyma (Kennedy et al., 2007b).

The low scattering contrast between cellulose and other cell wall polymers makes the analysis of X-ray scattering patterns difficult. Small Angle Neutron Scattering (SANS) provides an advantage over SAXS in this context. Because hydrogen scatters much more strongly than deuterium, neutron scattering contrast can be enhanced by replacing $\mathrm{H}_{2} \mathrm{O}$ with $\mathrm{D}_{2} \mathrm{O}$, or by deuterating components of the cell wall. A SANS study of primary cell walls in celery collenchyma characterized the microfibril diameter and shape (Thomas et al., 2013). The diameter was found to be about $2.9-3.0 \mathrm{~nm}$ and this value corresponds to 24 chains in a microfibril with a rectangular cross-section. These results of microfibril diameter and cross-section were similar to the findings of a SANS study of secondary cell wall in spruce wood; nevertheless, the presence of extensive disorder in primary cell walls prevented a conclusive result (Fernandes et al., 2011).

A challenge with scattering approaches is that, in principle, multiple structures can lead to the same scattering profiles. 
Thus, complementary data is crucial to develop structural models capable of explaining scattering data. This is especially true for primary cell walls, which exhibit poorly ordered packing, and as a consequence, scattering data from these tissues is more challenging to interpret. As such, the application of spectroscopic techniques, such as SS-NMR and IR, to primary cell walls is important to complement scattering and microscopy.

One early report that combined spectroscopy with imaging investigated onion and quince cell walls with fibril diameters established by electron microscopy of 8-10 nm and $2 \mathrm{~nm}$, respectively (Ha et al., 1998). The authors proposed that six microfibrils aggregate in onion, such that each elementary fibril is about $2 \mathrm{~nm}$; a strongly charged hemicellulose coating in quince is proposed to keep these microfibrils isolated. Two independent approaches were adopted for measuring the crystallite diameter, by calculating the proportion of surface to interior chains and through spin-diffusion experiments to measure the distance between surface and interior chains. Altogether, the two methods suggest that fibrils from onion and quince have similar crystallite diameters of approximately $2 \mathrm{~nm}$.

The lateral dimensions of cellulose crystallites from 10 different sources were estimated using ${ }^{13} \mathrm{C}$ NMR signal strengths (Newman, 1999). Signals at 89 and $85 \mathrm{ppm}$ were assigned to $\mathrm{C} 4$ in the interiors and on the surfaces of crystallites, respectively. Lateral dimensions were estimated from the relative signal areas under an assumption of a square microfibril cross-section. When compared with XRD results of the same samples, lateral dimensions obtained from NMR were found to be $10 \%$ higher, and this deviation was attributed to different molecular conformations of surface and interior chains that lead to broadening of XRD peaks. Using the same aforementioned peak assignment of surface and interior chains, NMR was also used to study the microfibril diameter of celery collenchyma and the results compared with that obtained from XRD and SAXS (Kennedy et al., 2007a). Assuming a constant microfibril diameter and circular model for its cross-section, the microfibril radius is calculated as:

$$
\frac{A_{\mathrm{I}}}{A}=\frac{(R-S)^{2}}{R^{2}}
$$

where $A_{\mathrm{I}} / A$ is the relative area of signals from interior chains, $R$ is the radius, and $S$ is the thickness of the surface monolayer of chains calculated from cellulose I $\beta$ lattice parameters as previously reported (Nishiyama et al., 2003). If no structural difference between surface and interior chains is assumed, the size of microfibrils obtained from NMR is in agreement with XRD results. Thus, NMR measurements can reconcile with the entire range of SAXS measurements depending on the different rotational orientation of surface chains that is assumed.

In addition to NMR, IR spectroscopy has been used to extract estimates of the microfibril size in higher plants, algae, and tunicates (Horikawa et al., 2009). This approach is based on an initial deuteration of $\mathrm{OH}$ groups in the entire crystalline region followed by re-hydrogenation at $25^{\circ} \mathrm{C}$ during which deuterated (OD) groups on the surface become re-hydrogenated $(\mathrm{OH})$. Microfibril dimensions were then estimated from the absorbances $(A)$ of $\mathrm{OD}$ and $\mathrm{OH}$ groups. Defining $R$ as an empirical parameter that is the ratio of the OD absorbance $\left(A_{\mathrm{OD}}\right)$ to the total absorbance by $R=$ $A_{\mathrm{OD}} /\left(A_{\mathrm{OH}}+A_{\mathrm{OD}}\right)$ can then enable comparison with other measures of the microfibril diameter. Indeed, $R$ was found to be highly correlated to the full width at half maximum of the (200) peak in XRD. Microfibrils were proposed to be flat based on the behavior of the re-hydrogenation process under heat treatment, which was consistent with observations by electron microscopy.

More recently, detailed studies on the cross-sectional shapes of cellulose crystallites and the number of chains in each microfibril have been attempted through spectroscopic techniques. These methods also provide valuable insights into aggregation and twinning of microfibrils, as well as conformational and packing disorder. SS-NMR and IR were used in combination with SANS and XRD to study the microfibril structure of spruce wood (Fernandes et al., 2011). The results of these studies favored a 24-chain model with a rectangular microfibril cross-section and the presence of twisting and disorder that increases toward the surface. Another study on celery collenchyma used NMR and IR of deuterated samples in combination with XRD, SANS, and WANS (neutron diffraction) (Thomas et al., 2013). This study suggests a 24-chain model with eight hydrogen bonded sheets of three chains and also the possibility of an 18-chain model if the presence of a hemicellulose chain is included. It also proposed the presence of high disorder in conformation, packing, and hydrogen bonding. Simulations of XRD profiles were compared with synchrotron XRD data and NMR results to predict the number of chains in microfibrils (Newman et al., 2013). The number of chains in a microfibril was estimated using the crystallinity $x$ estimated from NMR spectra (Newman, 1999). The uncertainties involved in the estimation of $k$ (shape factor) and $x$ made it difficult to make a precise estimate, and a possibility of 17-22 chains was suggested. The study ruled out a 36-chain model on the basis of predicted peaks that did not match with the experimental diffractogram. Good fits were obtained for 24and 18-chain models, with an even better fit for the 18-chain model with mixed cross-sectional shapes and the presence of occasional twinning.

Furthermore, studies of the cellulose synthase complex suggest a rosette that is a hexamer composed of trimers (Hill et al., 2014; Nixon et al., 2016; Vandavasi et al., 2016), which would be consistent with an 18-chain model. Using this as a starting point, a detailed study that combines X-ray diffraction and NMR data with predictions from computer simulations established a 5-layer cross-section with a 34443 chain arrangement as most probable (Kubicki et al., 2018). The ability to compare predicted and measured ${ }^{13} \mathrm{C}$ NMR shifts and diffraction spectra was able to rule out a $6 \times 3$ arrangement as highly unlikely, although a 6-layer 234432 cross-section is only slightly less likely than the 34443 configuration.

\section{Cellulose Microfibril Angle}

In contrast to the dispersed cellulose orientation of primary cell walls, cellulose microfibrils in woods are wound around the cell in a helical manner whose pitch is defined by the microfibril angle (MFA), which is described as the angle that the microfibrils 
make with the long axis of the cell (Barnett and Bonham, 2007). Traditionally, the MFA has been used to describe the orientation of cellulose microfibrils in the S2 layer of secondary walls in woods because cellulose makes up the greatest proportion of the wall thickness and most affects the macroscopic physical properties (Senft and Bendetsen, 1985). The S2 MFA has a significant influence on tensile strength, stiffness, and shrinkage in wood (Cave, 1968). Both the longitudinal tensile strength and stiffness of wood have been shown to be markedly affected by MFAs; as the MFA increases, tensile strength and stiffness quickly decrease (Altaner and Jarvis, 2008). The MFA is also an important determinant of quality of wood products. It has a major effect on the stability of wood on drying and subsequent manufacturing processes (Zobel, 1961).

The techniques for measuring MFAs can be grouped into four categories: (1) Polarized light microscopy, (2) direct visualization through microscopy after physical or chemical treatment such as iodine staining, (3) XRD and SAXS, and (4) Near IR (NIR) spectroscopy. A detailed review of these techniques and their comparison is available (Donaldson, 2008), and a brief summary of results from various techniques is shown in Table 4.

Extracting MFAs from polarized light microscopy involves rotating cellulose fibers relative to the fiber long axis until the maximum extinction position (MEP) is reached, which occurs when the bright cell wall becomes dark (Preston, 1934; Page,

TABLE 4 | Microfibril angle from different sources of cellulose obtained through the use of different characterization techniques.

\begin{tabular}{|c|c|c|}
\hline Source of cellulose & Microfibril angle $\left({ }^{\circ}\right)$ & Techniques* \\
\hline \multirow[t]{2}{*}{ Picea abies } & $\begin{array}{l}\leq 5 \text { (earlywood), } 20 \\
\text { (latewood) }\end{array}$ & SAXS (Jakob et al., 1994) \\
\hline & $\begin{array}{l}8 \text { (earlywood), } 9 \\
\text { (latewood) }\end{array}$ & XRD (Sahlberg et al., 1997) \\
\hline \multirow[t]{4}{*}{ Picea excelsa } & $32-35$ (normal wood) & $\begin{array}{l}\text { XRD (Kantola and } \\
\text { Seitsonen, 1961) }\end{array}$ \\
\hline & $\begin{array}{l}39-43 \text { (compression } \\
\text { wood) }\end{array}$ & \\
\hline & 18 (normal wood) & $\begin{array}{l}\text { SAXS (Kantola and } \\
\text { Kähkönen, 1963) }\end{array}$ \\
\hline & $\begin{array}{l}25-45 \text { (compression } \\
\text { wood) }\end{array}$ & \\
\hline Cedar (branch) & $39-57$ & PLM (Preston, 1934) \\
\hline Japanese larch & $37-79$ & PLM (Preston, 1934) \\
\hline Abies nobilis & $23-69$ & PLM (Preston, 1934) \\
\hline Virginia pine & 20 & PLM (Mark, 1967) \\
\hline \multirow[t]{2}{*}{ Loblolly pine } & $4-25$ (latewood) & SM (Hiller, 1964) \\
\hline & $19.22-34.06$ & NIR (Jones et al., 2005) \\
\hline Slash pine & $10-40$ (latewood) & SM (Hiller, 1964) \\
\hline \multirow[t]{2}{*}{ Douglas fir } & $\begin{array}{l}20 \text { (early \&and normal } \\
\text { wood) }\end{array}$ & XRD (El-osta et al., 1973) \\
\hline & $7-30$ & $\begin{array}{l}\text { PLM (Erickson and Arima, } \\
\text { 1974) }\end{array}$ \\
\hline \multirow[t]{2}{*}{ Pinus radiata } & $10.7-41.6$ & NIR (Schimleck et al., 2002) \\
\hline & $12-27$ & $\begin{array}{l}\text { PLM (Boyd and Foster, } \\
\text { 1974) }\end{array}$ \\
\hline
\end{tabular}

*PLM:, polarized light microscopy; SM:; staining methods; NIR:; near IR spectroscopy; XRD:, X-ray diffraction; SAXS:, small angle X-ray scattering.
1969). The difference between the fiber axis and MEP gives an estimate of an average MFA. A disadvantage of this technique is that it requires samples consisting of a single cell wall, otherwise the orientation of microfibrils in opposing cell walls in front and back walls will inhibit accurate determination of the MEP (El-Hosseiny and Page, 1973).

Brightfield microscopy and confocal microscopy have been used to measure MFAs in iodine stained samples (Bailey and Vestal, 1937; Senft and Bendetsen, 1985; Donaldson and Frankland, 2004). This method involves precipitation of iodine crystals within the cell wall and hence, it is limited by the fact that not all wood samples react well with iodine; thus, iodine does not always uniformly disperse in all the cells. Because iodine sublimes fast, the measurements have to be taken rapidly. Higher accuracy measurements of MFAs were facilitated through high contrast images taken with confocal reflectance microscopy (Donaldson and Frankland, 2004) or electron microscopy (Wardrop and Preston, 1947; Frei et al., 1957; Dunning, 1968).

$\mathrm{X}$-ray diffraction is perhaps the most commonly used method for determination of MFAs. Typically, MFA is obtained from XRD through the azimuthal distribution of the cellulose (200) equatorial reflection (Cave, 1968; Nelmes and Preston, 1968; Yamamoto et al., 1993). This method assumes that the cellulose crystals do not have a preferred orientation around the microfibril axis. SAXS can also provide MFA in a similar manner as XRD without this assumption (Jakob et al., 1994; Reiterer et al., 1998). SAXS has been used to estimate MFA in primary cell walls of single celled alga Chara corallina and multicellular hypocotyl of $A$. thaliana (Saxe et al., 2014). The work shows a bimodal MFA distribution such that the bulk of the microfibrils are oriented either transversely or longitudinally with broad scattering. The highly oriented microfibrils in secondary walls give an anisotropic SAXS pattern and the azimuthal intensity distribution of the resulting streaks is used to extract information on the distribution of MFA. This method has been adopted for wood cells in Picea abies (Jakob et al., 1994; Reiterer et al., 1998). These studies found that stiffer parts of trees have lower MFA when compared to the more flexible parts that have higher MFA, thereby supporting the correlation between cellulose MFA and mechanical properties of the cell wall.

Near IR spectroscopy has also been used to predict MFA by examining wood surfaces on the radial-longitudinal face (Jones et al., 2005; Schimleck et al., 2005). The method uses XRD data for calibration, and thus becomes inaccurate for higher angles because XRD data are less precise at high angles due to a reduced signal-to-noise ratio for the (200) reflection of the diffraction pattern (Schimleck et al., 2005).

\section{Spatial Organization of Cellulose Microfibrils}

Because cellulose microfibrils are the structural units of primary cell walls, the spatial arrangement of these microfibrils, including their bundling and packing, strongly impacts cell wall mechanics and growth. Traditionally, the mesoscale arrangement of microfibrils was studied largely by electron microscopy. The technique provided many valuable insights about the 
microstructure in cell walls, such as the development of networklike morphologies in growing cells of maize and oats coleoptiles (Mühlethaler, 1950). Microfibrils form a loosely reticulated network in a newly deposited cell wall, and gradually stiffen the wall with the addition of new microfibrils. Electron microscopy has also been used to study the cell wall architecture of near native onion primary cell walls at high resolution through shadowed replicas of rapidly frozen, deep-etched specimens (McCann et al., 1990). This study suggests hemicelluloses form the cross-links between cellulose microfibrils, and indicated a lamellate model for cellulose organization; microfibrils are co-aligned within each "lamellae," multiple lamellae (ca. 100) are stacked on top of each other, but the net orientation of each lamellae is not necessarily correlated to other lamellae. Various aspects of this model were challenged by further work on native tissues, as described below.

Although limited to the structure near the surface, SEM and AFM provide an opportunity to image the spatial arrangement of microfibrils in primary cell walls. SEM has been demonstrated as a powerful tool to examine microfibril organization and will be discussed in more detail in the next section in the context of examining the interaction between cell wall components; AFM provides a relatively unique capability of imaging cell walls in their native state. For example, detailed observations of the primary cell walls of onion and Arabidopsis have elucidated multiple aspects of the cellulose network structure. Contrary to reports based on electron microscopy (McCann et al., 1990), high resolution images of microfibrils in their native state for onion did not support the hypothesis of microfibrils cross-linked by hemicellulose. Instead, AFM images show microfibril bundles with single microfibrils emerging in and out to form a reticulated network (Zhang et al., 2014, 2016). Figure 7 shows a montage of high resolution AFM images of onion where the alignment of microfibrils and extensive microfibril bundling is visible. Often, multiple layers are visible, such that the relative orientation of the layers can be examined. The studies suggest a crossed polylamellate wall structure instead of a helicoidal arrangement.

As a complementary technique to AFM, fluorescence microscopy can characterize cellulose microfibrils with high sensitivity and selectivity to chosen markers despite low spatial resolution $(\sim 200 \mathrm{~nm})$. Xyloglucan binding proteins, galactan-binding proteins, or antibodies have been used with fluorescent labels for visualizing the distribution of hemicellulosic components in cell walls (Hayashi and Maclachlan, 1984; Brunecky et al., 2008; Sandquist et al., 2010). Nevertheless, the large size of these proteins restricts penetration into interstitial spaces and nano-sized pores within the cell wall structure. The search for smaller probes led to the discovery of Carbohydrate Binding Modules (CBM) as suitable molecular probes for highresolution fluorescence microscopy because of their compact size and specificity toward targeted substrates. According to their substrate specificity, CBMs are classified as Types A, B, and C, where Type A binds to the surface of crystalline polysaccharides, $\mathrm{B}$ binds internally to glycan chains, and $\mathrm{C}$ binds to termini of glycan chains (Gilbert et al., 2013). Fluorescence microscopy with CBMs as molecular probes has been used to investigate the structure of cellulosic material both in native and treated samples (Porter Stephanie et al., 2007; Kawakubo et al., 2009; Široký et al.,
2016). In addition, confocal microscopy with the fluorescent dye Pontamine Fast Scarlet 4B (S4B), a stain that shows higher specificity for cellulose than for other cell wall components, has been used to study the cell wall architecture and dynamics of cellulose microfibrils in growing cell walls of $A$. thaliana root cells (Anderson et al., 2010). Confocal fluorescence microscopy images from this study supported the passive reorientation theory of cellulose microfibrils, which states that newly deposited cellulose microfibrils are transversely oriented to the longitudinal axis and the microfibrils reorient during expansion. Figure $\mathbf{8}$ shows confocal images of cellulose orientation in different cell wall layers using the S4B stain. As a function of time, the cellulose microfibrils reorient from approximately $47-30^{\circ}$ with respect to the long axis of the epidermal cells.

Scattering methods again provide a complementary approach to microscopy. Ultra-small angle (USAXS) and very smallangle X-ray scattering (VSAXS) are being used with SAXS to study the hierarchical structure of cellulose. USAXS can probe length scales from 1 to $10 \mu \mathrm{m}$, thus enabling the study of microfibril bundles or aggregates, while VSAXS can probe length scales intermediate between that of SAXS and USAXS. The scattering patterns of untreated and pre-treated maize using these techniques reveal the presence of structures with sizes in between microfibrils of $30 \mathrm{~nm}$ diameter (likely microfibril aggregates) and $140 \mathrm{~nm}$ bundles (Inouye et al., 2014; Zhang et al., 2015). Yet, details regarding the origin of these scattering features remain elusive.

Another approach to examine the spatial arrangement of cell walls is based on SFG. The non-centrosymmetry and phase matching requirements and the coherence length on the order of hundreds of nanometers lead to signatures of the spatial organization of crystalline cellulose dispersed in amorphous matrices. In particular, the overall SFG intensity, the alkyl peak shape, and the alkyl/hydroxyl intensity ratio have been shown to depend on the mesoscale assembly of cellulose, such as the lateral packing and net directionality of microfibrils (Lee et al., 2014). Recent work shows that SFG can detect the difference in arrangement of cellulose microfibrils between primary and secondary cell walls (Lee et al., 2014, 2015a). On the basis of the $\mathrm{CH} / \mathrm{OH}$ relative intensity in SFG, it was suggested that over the SFG coherence length, primary cell walls have a lower degree of antiparallel orientation of cellulose microfibrils (Lee et al., 2014). Furthermore, control samples with uniaxially aligned cellulose crystals in amorphous matrices were examined to identify spectral signatures corresponding to the distance between microfibrils, and these signatures are supported with predictions of the spectra. The work on these model systems suggests that the $\mathrm{CH} / \mathrm{OH}$ intensity ratio in SFG spectra decreases non-linearly as the intercrystallite distance increases (Makarem et al., 2017). In addition, because SFG can be performed on hydrated samples, the effect of drying has been examined. Reversible changes in the SFG spectra with dehydration and rehydration were attributed to the presence of local strains due to drying (Huang et al., 2018). The consequence of such strains could be to perturb the packing of cellulose, thereby affecting the width and position of diffraction peaks. Further work is needed to determine the consequences of drying, and to ensure that 
$\mathrm{X}$-ray and electron beam techniques that rely on dry samples yield reliable and biologically relevant structural information.

The aforementioned techniques provide valuable insights into the arrangement of cellulose microfibrils in cell walls. Nevertheless, relating cell wall structure with cell growth and mechanics requires an understanding of the interaction of cellulose with other matrix polysaccharides. The different approaches and techniques focused in this area are discussed in the following section.

\section{INTERACTION OF CELLULOSE MICROFIBRILS WITH OTHER MATRIX POLYSACCHARIDES}

Cell wall properties are dependent upon the combined structure, chemistry, and mechanical properties of the constituents (Chebli and Geitmann, 2017). Cellulose-cellulose and cellulose-matrix interactions influence the strength and extensibility of cell walls, thus contributing to the regulation of cell growth. The major non-cellulosic polymers in primary walls are different from those in secondary walls (Cosgrove and Jarvis, 2012). Xyloglucans and pectin are dominant in primary walls, and the current structural model of the primary wall depicts a cellulose-hemicellulose network embedded in a pectin matrix. These constituents form the crucial load bearing components. In secondary walls of coniferous wood, cellulose microfibrils form aggregates with adjacent microfibrils directly attached to each other over part of their length, and most of the hemicellulose and lignin lie out of these aggregates, with glucomannans more closely associated with the microfibrils (Fernandes et al., 2011). These structural models were derived from chemical analysis, biochemical studies, and electron and optical microscopies (Carpita and Gibeaut, 1993; Sarkar et al., 2009). New approaches to examine the interaction of cellulose and matrix polysaccharides involve scattering, spectroscopy, and microscopic techniques, such as AFM and FESEM. The following section discusses the application of these techniques to investigate interactions between cellulose and matrix polysaccharides.

The heterogeneity of the cell wall composition complicates the application of characterization techniques to the whole cell wall. Methods to isolate interactions of specific wall components can be roughly classified in one of two ways: (i) top-down approaches and (ii) bottom-up approaches (Martínez-Sanz et al., 2015a). The top-down approach involves investigating the effects of removal of non-cellulosic components on the structure of the cell wall, while the bottom-up approach involves the incorporation of additives into the culture media of cellulose-producing bacteria to mimic the assembly process taking place during plant cell wall biosynthesis. Bottom-up approaches are limited in relevance to primary cell walls given that a detailed description of cell wall assembly is currently not available; nevertheless, such studies are potentially informative as we learn more about cell wall structure and assembly and we thus briefly discuss them here.

In the top-down approach, non-cellulosic components of the cell wall can be removed by techniques including enzymatic hydrolysis and acid hydrolysis (Pingali et al., 2010), and by treatment with base (Jungnikl et al., 2007), steam (Pingali et al., 2014), or ionic liquids (Cheng et al., 2011). The effects of enzymatic hydrolysis on the structure of the cellulose network have been widely studied by SAXS and SANS (Kent et al., 2010; Penttilä et al., 2010, 2013). These studies suggest that hydrolytic digestion proceeds from the outer surface and very often cannot penetrate into the substrate interior without agitation of the sample. In addition, SEM and TEM have been extensively used to follow structural changes in the cell wall after biomass pre-treatment (Sant'Anna and de Souza, 2012). SEM is the method of choice to describe anatomical features and degradation at cellular- and nano-resolution of biomass surfaces, while TEM is combined with techniques including ultra-thin sectioning, rapid-freezing followed by deep etching, ultrastructural cytochemistry, immunogold, and electron tomography to investigate ultrastructural changes in the cell wall. In a recent study, FESEM was used to investigate fiber bundling, organization, and the spatial location and conformation of xyloglucans in onion cell walls (Zheng et al., 2018). FESEM imaging was combined with digestions by substrate-specific endoglucanases and labeling with nanogold affinity tags for cellulose and xyloglucan (Figure 9). The study provided evidence of coverage of cellulose surfaces by xyloglucan to some extent, but distinct xyloglucan structures could not be imaged. In particular, a lack of evidence for xyloglucan tethered to multiple microfibrils suggests xyloglucan does not serve as load-bearing links between microfibrils.

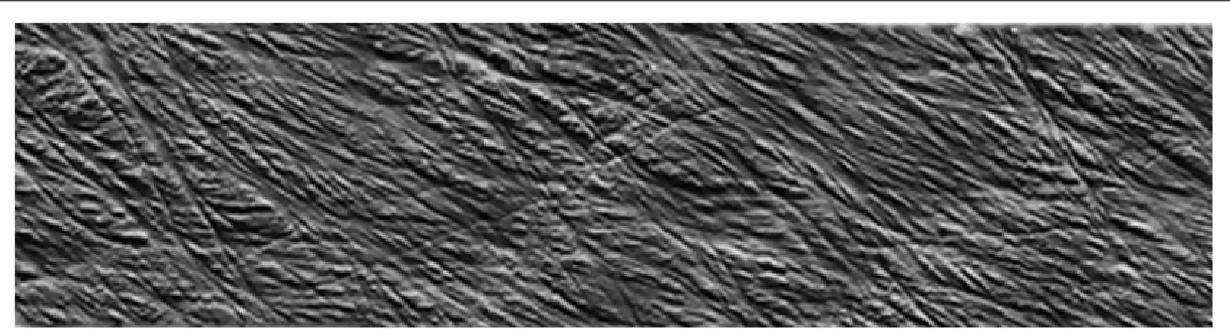

FIGURE 7 | Atomic Force Microscopy micrograph of cellulose microfibrils merging in and out of microfibril bundles. Reprinted with permission from Zhang et al. (2016). Spatial organization of cellulose microfibrils and matrix polysaccharides in primary plant cell walls as imaged by multichannel atomic force microscopy. The Plant Journal 85, 179-192. Copyright @ 2016, John Wiley and Sons. 

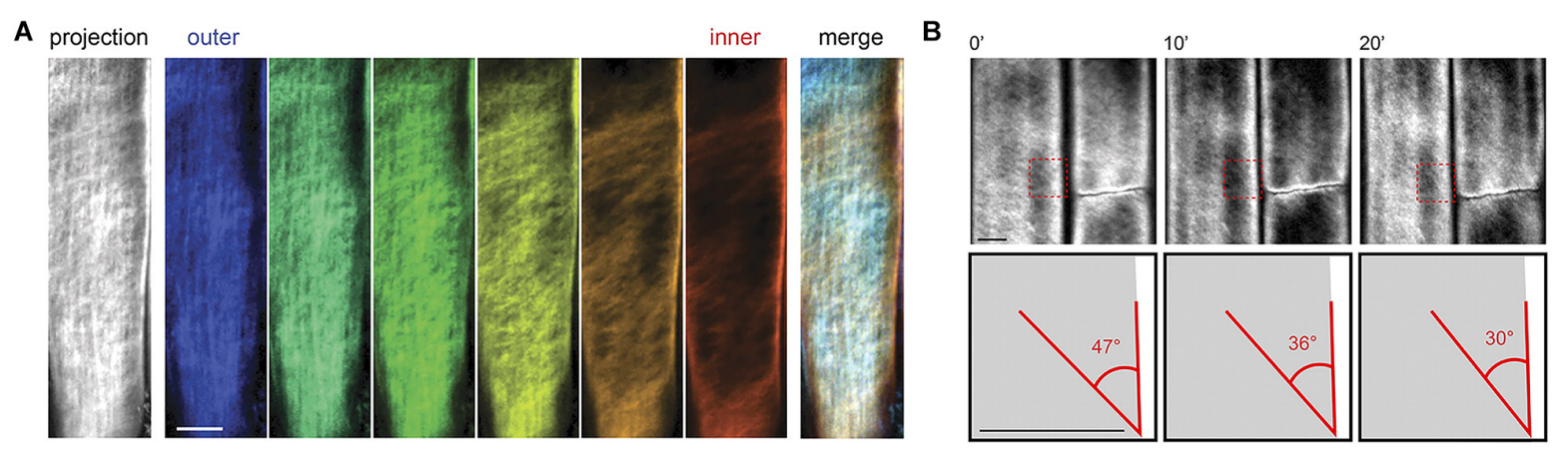

FIGURE 8 | Confocal microscopy images showing (A) cellulose orientation in different cell wall layers using S4B staining, and (B) rotation of stained microfibrils over time in Arabidopsis. Reprinted with permission from Anderson et al. (2010). Real-Time Imaging of Cellulose Reorientation during Cell Wall Expansion in Arabidopsis Roots. Plant Physiology 152 (2), 787-796. www.plantphysiol.org. Copyright (C) 2010 American Society of Plant Biologists.

Atomic force microscopy has also been applied to study the effect of chemical extraction procedures on the structure of cellulose microfibrils (Davies and Harris, 2003; Kirby et al., 2006). In a study of the effect of thermochemical treatment on maize cell wall (Chundawat et al., 2011), the ability of the AFM tip to differentiate between hydrophobic and hydrophilic regions was used to reveal that the native cell wall is mostly hydrophobic. Nevertheless, after thermochemical treatment, hydrophilic regions were found. An increased surface roughness could also be measured by AFM.

Alternatively to extraction, mutants have been used to examine the effects of modifying cell wall compositions and reveal interactions between cellulose and matrix components. Xyloglucan deficient mutants of A. thaliana ( $x x t 1 x x t 2)$ show highly aligned cellulose microfibrils in AFM images of the cell wall (Xiao et al., 2016). This increase in local order suggests that xyloglucan mediates interactions between cellulose microfibrils, as a spacer molecule that promotes microfibril dispersion within the cell wall. Pectin mutants of $A$. thaliana $\left(P G X 1^{\mathrm{AT}}\right.$ ) lead to shorter homogalacturonan, and ${ }^{13} \mathrm{C}$ solidstate NMR reveals perturbations to the pectin-rich matrix and pectin-cellulose interactions in the cell walls of these plants (Phyo et al., 2017). The overall larger growth of pectin mutants and ${ }^{13} \mathrm{C}$ NMR characterization suggests that the pectin matrix influences wall dynamics during cell growth. The ongoing studies of mutants will continue to reveal fundamental interactions between cell wall components.

Another approach relies on labeling of components to provide sensitivity to specific interactions. Multidimensional solid-state NMR (MAS SS-NMR) spectroscopy, coupled with ${ }^{13} \mathrm{C}$ labeling of whole plants, enabled study of the spatial arrangement of cell wall polysaccharides in near-native cell walls. The analyses of cross-peaks in two- and three-dimensional MAS SS-NMR of ${ }^{13} \mathrm{C}$ labeled $A$. thaliana suggests that cellulose forms a single network with pectin and xyloglucans (Wang and Hong, 2016). The technique also revealed the existence of pectin-cellulose close contacts in primary cell walls (Wang et al., 2012). ${ }^{13} \mathrm{C}$ SS-NMR of mung bean cell walls detected xyloglucans of different mobilities including rigid and partly rigid (Bootten et al., 2004); the study suggests that the partly rigid xyloglucans are predominant in the cell wall. In addition, polarization transfer in SS-NMR has been used to study water-polysaccharide interactions in primary cell walls of Arabidopsis. Results on water-pectin and watercellulose spin diffusion support the single network model of the primary cell wall (White et al., 2014). Furthermore, MAS NMR of Arabidopsis stems revealed that xylans are found in both two and threefold screw conformations (Simmons et al., 2016). The twofold conformation is required for xylans to bind onto cellulose microfibrils.

Bottom-up approaches use a cellulose-producing bacteria such as Gluconacetobacter xylinus as a model system for the study of cellulose-matrix polysaccharide interactions. Cell wall polysaccharides like hemicellulose and pectin are incorporated into the culture media of the bacteria and composite pellicles are produced. The bacterial cellulose composites can then be used to examine how matrix polymers affect cellulose crystallization and how cellulose interacts with matrix polysaccharides. For example, XRD, SAXS, and SANS have been used widely to study composite pellicles with cell wall polysaccharides including xylan, xyloglucan, arabinoxylan, mannan, and pectin (Astley et al., 2001; Gu and Catchmark, 2012; Martínez-Sanz et al., 2015b). SAXS and XRD studies revealed that addition of xyloglucan affects the cellulose microfibril packing and crystalline structure; in contrast, addition of arabinoxylan does not impact these features of the cellulose network (Martínez-Sanz et al., 2015b). Spectroscopy and microscopy can also be used to examine the cellulose network within composite pellicles; nevertheless, the pellicles are highly hydrated and have strong aggregation tendency, so structural artifacts may be introduced during the drying process that is required for analysis. Recent SANS studies demonstrated that controlled incorporation of deuterium into bacterial cellulose does not introduce any structural changes in bacterial cellulose (Bali et al., 2013; He et al., 2014). The deuterated bacterial cellulose will have applications in elastic and inelastic neutron scattering experiments for studying cellulose structure and dynamics and interactions with wall polysaccharides.

Similar to scattering techniques, spectroscopic techniques including IR, Raman, SFG, and NMR have also been used to investigate interaction among cell wall components through both top-down and bottom-up approaches. IR spectroscopy has been 
used to study the changes in cellulose polymorphism on addition of xyloglucan, xylan, arabinogalactan, and pectin to bacterial cellulose (Tokoh et al., 1998, 2002; Gu and Catchmark, 2012). Addition of xylan and xyloglucan results in an increase in the levels of cellulose I $\beta$ and a decrease in crystallinity. Xyloglucan has a larger impact on cellulose assembly than pectin as addition of xyloglucan decreases crystallinity and increases disorder in the cellulose structure, but addition of pectin has no effect (Gu and Catchmark, 2012).

\section{OPPORTUNITIES IN STRUCTURAL CHARACTERIZATION OF PLANT CELL WALLS}

The on-going development of instrumentation and techniques for the study of soft matter structure leads to new opportunities in the structural characterization of cell walls. In this section, we highlight some emerging techniques based on diffraction/scattering, imaging, and spectroscopy that may facilitate the creation of new knowledge on cell wall structure and assembly.

\section{Diffraction and Scattering}

The high brilliance of synchrotron radiation sources has enabled the application of X-ray microbeam diffraction and scattering techniques to weakly scattering samples like polymers and biopolymers. X-ray diffraction and scattering techniques can provide average structural parameters, but not information on local structures. Beam sizes of about $1 \mu \mathrm{m}$ and sub- $\mu \mathrm{m}$ sizes can provide abundant local information, such as the spatial heterogeneity of materials and the structural change at a local position. An advantage of scanning X-ray diffractometry when compared to transmission electron scattering experiments is
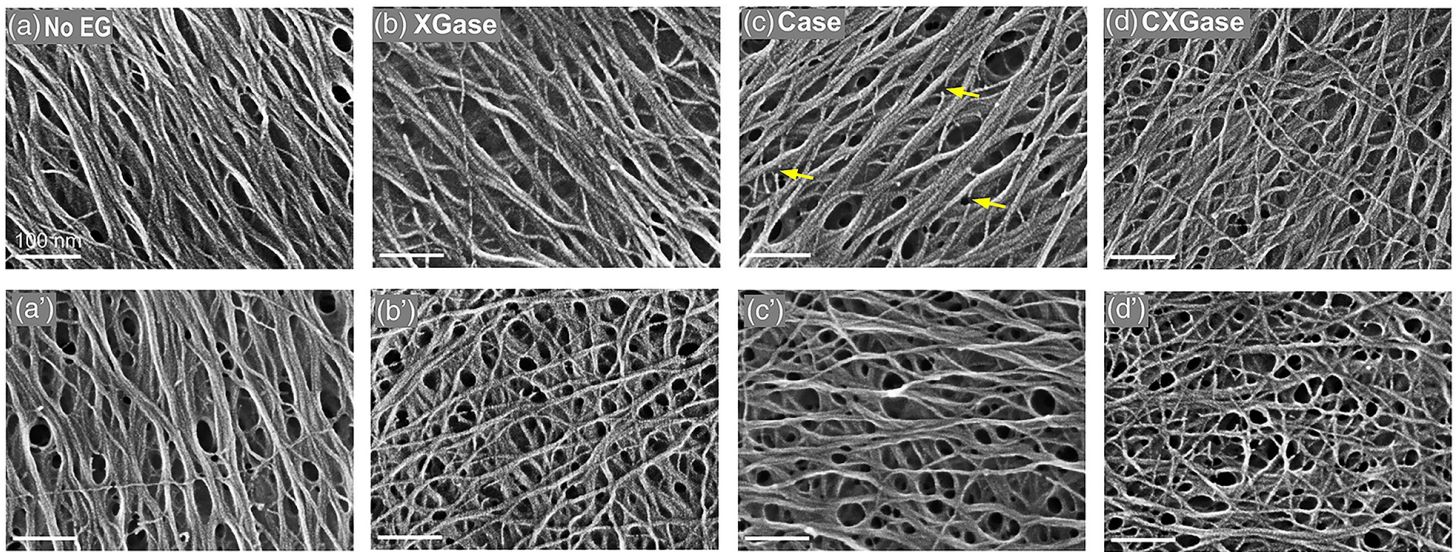

(e)

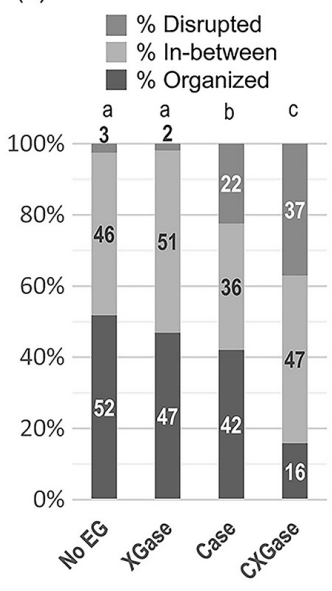

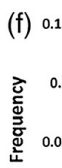
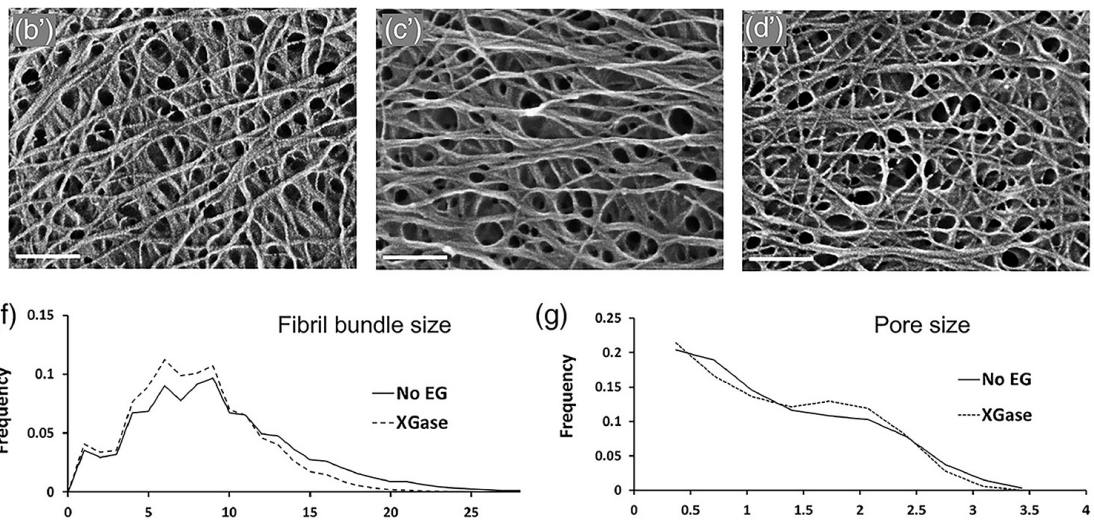

(g)
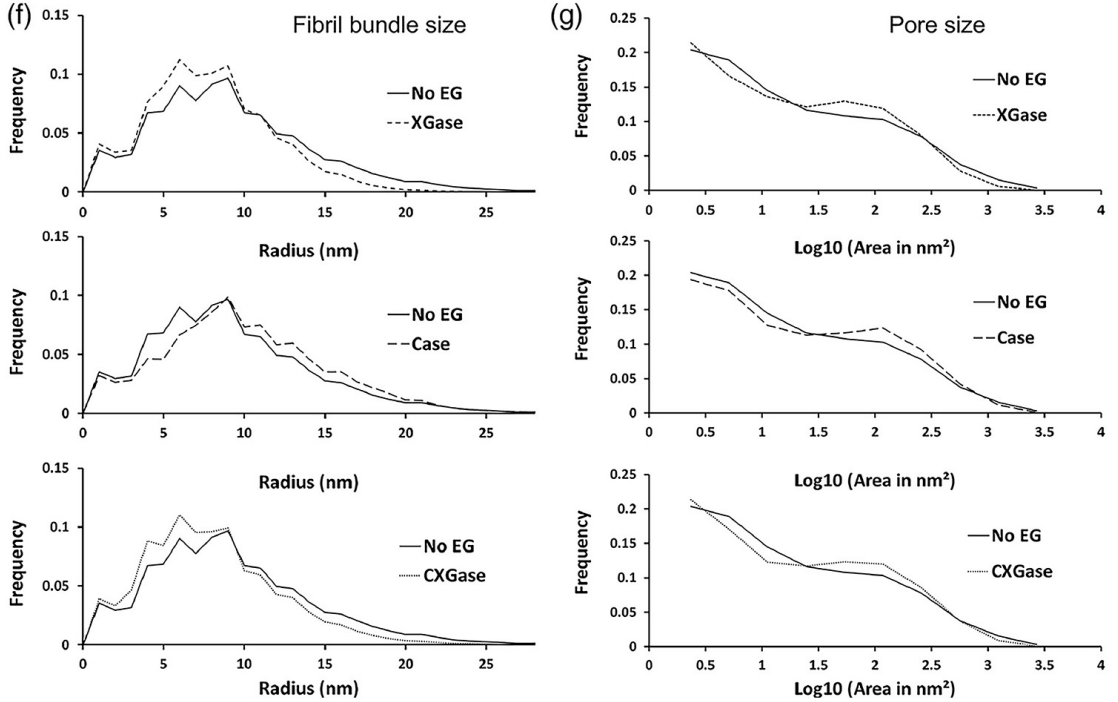

FIGURE 9 | Field emission scanning electron microscopy (FESEM) images of onion cell wall without enzyme treatment (a,a') and after different enzyme treatments (b-d,b'-d'). (e-g) Effect of treatments on wall properties. XGase is a family-12 glycosyl hydrolase (GH) that hydrolyzes xyloglucan but not unbranched glucan, Case is a family-12 GH that hydrolyzes non-crystalline cellulose only, and CXGase is a family-5 GH that hydrolyzes both non-crystalline cellulose and xyloglucan. No EG denotes no endoglucanase treatment. Reprinted with permission from Zheng et al. (2018). Xyloglucan in the primary cell wall: assessment by FESEM, selective enzyme digestions and nanogold affinity tags. The Plant Journal 93, 211-226. Copyright 2018, John Wiley and Sons. 
the ability to examine single fibers without the necessity for sectioning (Riekel, 2000).

The application of position-resolved synchrotron X-ray microdiffraction with beam size less than the thickness of a single cell wall enabled the imaging of the helical arrangement of cellulose microfibrils in cell walls of Norwegian spruce (Lichtenegger et al., 1999; Peura et al., 2005). X-ray microbeam diffraction has also been used to study the orientation, crystallite size, and crystallinity of cellulose microfibrils from various sources, including viscose rayon fibers (Müller et al., 2000), Japanese Cedar (Müller et al., 2002), and Norway spruce (Peura et al., 2007). For techniques aiming at analyzing small sample volumes, X-ray microdiffraction has a clear advantage over transmission electron microscopy/diffraction in terms of sample preparation and acquisition time. The application of SAXS with a beam size of a few micrometers ( $\mu$ SAXS) revealed the strong alignment of cellulose microfibrils within single native flax fibers (Müller et al., 1998). Such position-resolved studies could potentially resolve the super-molecular structure of cellulose microfibrils.

Grazing Incidence Wide Angle X-ray Scattering (GIWAXS) is another synchrotron based technique (although it is becoming available in lab-scale instruments) that may be useful for primary plant cell walls. GIWAXS probes not only the surface but also beneath it. Because of its grazing incidence geometry, GIWAXS is a promising scattering technique for weakly scattering and fragile cell wall samples. The large beam footprint produces a better signal-to-noise ratio and also causes less radiation damage. GIWAXS with a 2D detector can reveal net orientation of crystals, ca lled texturing (Baker et al., 2010 \#690; Gomez et al., 2011 \#1026; Rivnay et al., 2012 \#3971). GIWAXS data from a cell wall sample can be used to estimate the degree of preferred orientation and crystallinity of cellulose crystals, which has not been previously demonstrated.

Resonant soft X-ray scattering (RSoXS) is a combination of conventional SAXS with soft X-ray spectroscopy that offers enhanced and tunable scattering contrast as well as elemental and chemical environment sensitivity (Virgili et al., 2007; Guo et al., 2013; Liu et al., 2016). Its large length scale accessibility, chemical sensitivity, and molecular bond orientation sensitivity makes RSoXS an attractive tool for studying different materials including biological assemblies. The different cell wall polysaccharides have similar electron density, so RSoXS could be useful in differentiating between them based on their chemical differences. Recent work has shown that RSoXS can reveal the structure of casein micelles and proteins by tuning to specific X-ray energies and thereby producing contrast between components (Ingham et al., 2015, 2016; Ye et al., 2018b). Furthermore, work on onion scales has demonstrated that tuning the X-ray energy to the Ca edge generates contrast between pectin and cellulose microfibrils, such that the spacing between microfibrils or microfibril bundles is revealed (Ye et al., 2018a). Thus, an opportunity exists to adopt a new chemically sensitive scattering technique for the study of plant cell walls.

In addition to X-ray scattering, there are opportunities for novel characterization approaches based on neutron scattering. Quasi-elastic neutron scattering (QENS) is sensitive to reorganization of atoms and molecules on a pico-second to nano-second time scale over length scales of 1-500 $\AA$. This broad spatial and temporal scale is ideal for studying complex biological systems as the scale is matched to atomic and molecular vibrational displacements, jump distances, and correlation lengths (Magazù and Migliardo, 2011). Because of the dependence of the relaxation times on the wave-vector, QENS can resolve spatial differences in the dynamics of water and biological macromolecules like proteins. The technique has also been applied to study water-cellulose dynamics in bacterial cellulose, which revealed the existence of two distinct populations of water in the bacterial cellulose system: surface water and water confined in the spaces between the microfibrils (O'Neill et al., 2017). Even though the nanoscale structure and composition of bacterial cellulose is markedly different from plant cell walls, the feasibility of the study presents the technique as a promising tool for the study of native plant cell walls as well.

\section{Microscopy}

Recent advances in optical, X-ray, and electron imaging tools provide new opportunities for the study of cell walls. Optical microscopes cannot distinguish between two objects separated by a lateral distance less than approximately half the wavelength of light used to image the specimen. This resolution limitation is referred to as the diffraction limit. The diffraction limit for optical microscopy is about $200-300 \mathrm{~nm}$ in the lateral direction and $500-700 \mathrm{~nm}$ in the axial (vertical) direction for confocal microscopy, which makes subcellular structures too small to be resolved in detail. This presents a problem when optical microscopy is used to investigate plant cell wall features of about a few nanometers in size. In such cases, the signal collected by optical microscopy represents an ensemble average of signals from different wall constituents. Super Resolution Fluorescence Microscopy (SRFM) refers to a host of techniques that overcome the resolution limitation caused by the diffraction limit in conventional fluorescence microscopy (Huang et al., 2009). With SRFM, three-dimensional imaging with an optical resolution of about $20 \mathrm{~nm}$ in the lateral direction and $40-50 \mathrm{~nm}$ in the axial dimension has been achieved. These techniques can employ non-linear optical effects to reduce the size of the excitation point spread function through Stimulated Emission-Depletion (STED) or Saturated Structured Illumination microscopy (SSIM). Furthermore, some techniques are also based on the localization of individual fluorescent molecules, such as stochastic optical reconstruction microscopy (STORM), photoactivated localization microscopy (PALM), and fluorescence photoactivation localization microscopy (FPALM). Recent advances have enabled 3D imaging (Huang et al., 2008), multicolor imaging (Bossi et al., 2008), and live cell imaging (Westphal et al., 2007) with SRFM.

Another approach to increase the spatial resolution beyond the diffraction barrier relies on combining near-field optical techniques with scanning probe microscopy. Near-field scanning optical microscopy (NSOM) obtains high optical and spatial resolution through the use of a tapered optical fiber with a sub-wavelength aperture of about $100 \mathrm{~nm}$ in diameter. Because these tips are made from optical fibers, they are fragile and 
easily damaged, which can lead to artifacts. Due to these issues, NSOM with aperture-less probes with tip enhancement are being used to compartmentalize signals collected from the near field and the far field (Fragola et al., 2004). Such an ability holds promise for characterization of plant cell walls as signals from different cell wall components could be differentiated. Other apertureless tip-enhanced imaging techniques that may be able to chemically characterize plant cell walls on the cellular scale are Tip-enhanced Raman imaging, Near-field coherent anti-stokes Raman Scattering microscopy and two-photon excitation fluorescence (TPEF) spectroscopy. The capabilities of these techniques have been discussed in detail in a review (Yarbrough et al., 2009).

Total Internal Reflection Fluorescence Microscopy (TIRFM) is well suited for optical sectioning at cell-substrate regions with a thin region of fluorescence excitation (Axelrod, 2001; Mattheyses et al., 2010). The laser beam is incident on the glasssubstrate interface at an angle beyond the critical angle. Due to the nature of the evanescent field, the excitation volume is large in the transverse dimension but highly confined in the axial dimension. This greatly reduces background fluorescence from out-of-focus planes and results in images with a very high signal-to-noise ratio. TIRFM has proven to be a powerful approach for examination of animal cells and for single-molecule experiments. It is particularly useful for analysis of dynamics of molecules and processes near the plasma membrane as it obscures the fluorescence from the bulk of the cell. Indeed, a recent study applied TIRFM to examine protein endocytosis in the plant plasma membrane (Johnson and Vert, 2017); however, application of TIRFM to the cell wall which lies adjacent to the plasma membrane has not yet been demonstrated. Furthermore, the use of multi-angle TIRFM opens the possibility of examining the distribution of proteins within plant samples in the axial direction (Fu et al., 2016).

High resolution can also be achieved using short-wavelength radiation. Scanning Transmission X-ray Microscopy (STXM) can generate microscopic images of a thin section of a specimen by raster-scanning a focused X-ray beam while the transmitted $\mathrm{X}$-ray intensity is recorded as a function of the sample position. This technique falls under the category of 'spectro-microscopy' as X-ray absorption spectra can be obtained from microscopic features of the sectioned sample. The technique is based on synchrotron radiation and leverages X-ray absorption spectra that are characteristic of chemical states of atomic species or crystalline structures of materials (Warwick et al., 1998). Thus, STXM is useful for elemental identification and spatial mapping of heterogeneous materials (Ade and Hitchcock, 2008). The main advantages of STXM are minimal radiation damage (when compared to electron microscopy), ability to analyze hydrated samples, and ability to probe alignment of molecular orbitals due to polarization dependence. Various STXM based techniques like C-XANES and C-NEXAFS have been used to carry out chemical analysis of plant biomass (Cody, 2000; Mancosky et al., 2005; Cody et al., 2009). STXM based spectrotomography is also able to do morphological $3 \mathrm{D}$ visualization and quantitative chemical mapping in bacteria (Wang et al., 2011).
STXM based on soft X-ray spectromicroscopy is a powerful technique that holds promise for characterization of plant samples with advantages of high spatial resolution and chemical sensitivity similar to mid infrared spectromicroscopy. The major problem in characterizing cell wall samples is the heterogeneous matrix and the spectra obtained are often dominated by the component in highest concentration. The use of X-ray fluorescent probes can be used with high resolution STXM to overcome the limitations of molecular sensitivity. Using the combination of confocal laser microscopy with fluorescent probes and STXM could be a valuable approach for studying plant cell wall samples. The approach has been demonstrated successfully in microbial biofilms (Lawrence et al., 2003).

Advances in TEM, and in particular in cryogenic transmission electron microscopy (cryo-TEM), provides new opportunities that are also based on short-wavelength radiation. Recent advances in direct electron detectors and automatic image acquisition have significantly advanced structural biology, as these instrumental developments allow for better signal to noise and acquisition of large data sets that can be averaged to improve resolution. The process begins with vitrification, in which the sample solution is rapidly cooled and water molecules form an amorphous solid instead of crystallizing. Resolutions of approximately $3 \AA$ or lower have been achieved by cryoTEM (Bartesaghi et al., 2015; Dellisanti, 2015). The technique can analyze large and complex biological assemblies that are often difficult to crystallize for X-ray crystallography or are too large and complex for NMR. 3D images of samples can be reconstructed from tilted $2 \mathrm{D}$ images through cryogenic electron tomography (cryo-ET). Both cryo-TEM and cryo-ET hold promise for characterization of plant cell walls as they allow analysis of the preserved hydrated state. The use of cryo-TEM to study the cell wall organization of Staphylococcus aureus has been demonstrated (Matias and Beveridge, 2006). Cryo-ET has also been used for $3 \mathrm{D}$ visualization of cell wall ultrastructure at a resolution of about $2 \mathrm{~nm}$ without isolation of cell walls (Sarkar et al., 2014). The microfibril diameter within Arabidopsis cell walls found from the study was comparable to diameters measured from AFM. Nevertheless, the sample preparation required for this approach is lengthy and arduous when compared to the more commonly used imaging techniques like AFM and FESEM. Application of faster sample preparation protocols might contribute to more routine use of the technique.

The use of ionizing radiation, as in X-ray or electron microscopy, is limited by the damage caused from the beam. An alternative approach is Scanning Acoustic Microscopy (SAM), which makes use of acoustic waves to create images of microscopic objects. Unlike optical microscopy, SAM does not require any staining or fixation, so it can be used for imaging live cells. Also, it can non-invasively observe not only the surface but also the internal structure of the specimen with sub-micron resolution. In addition, SAM is capable of measuring mechanical properties like the loss factor and modulus of tissues (Maeva et al., 2009). The interactions between ultrasonic waves and matter determine the size of the receiving signal and thus create contrast; contrast is generated on the basis of different acoustic impedances of different materials and is also due to absorption 
of acoustic waves in the material. Conventional SAM operates in the range of $20-200 \mathrm{MHz}$ while High Frequency SAM (HF-SAM) operates in the $0.4-2 \mathrm{GHz}$ range. HF-SAM has been used to study the hydrated primary cell wall of onion epidermis (Tittmann and $\mathrm{Xi}, 2014)$. In this study, SAM was able to detect that enzymatic removal of pectin influences the mechanical properties of primary cell wall. Thus, SAM presents potential as a powerful tool to study not only the structure and mechanics of the cell wall in its natural state but also the interactions between the different wall components through the top-down approach of enzymatic treatments.

As discussed earlier, microscopic techniques are widely used for direct visualization of plant cell walls. Nevertheless, only a few examples of quantitative image analysis have been reported. Typical image analysis includes determining particle sizes, area, length, porosity, and other useful measurements. The availability of open source and open architecture image processing software like ImageJ (Schneider et al., 2012) has contributed to the ability to readily quantify various parameters from microscopic images. For example, ImageJ has been used to process and analyze AFM images to quantify different cellulose microfibril parameters like width and orientation (Boudaoud et al., 2014; Kafle et al., 2014; Zhang et al., 2016, 2017). Several open source image analysis software packages including SOAX (Xu et al., 2015; Zhang et al., 2017) and FibreApp (Usov and Mezzenga, 2015) in addition to ImageJ offer immense opportunities to be used for quantitative analyses of microscopic images of cell walls.

Yet, quantitative analysis of microscopy images of the cell wall is still challenging as the structure is highly heterogeneous. It is even more difficult in primary cell walls due to the higher degree of disorder. A number of times, the arrangement of microfibrils have been reported to mimic a 'liquid crystal' like structure (Reis et al., 1991; Himmel et al., 2007). The molecules in such structures seem to have a certain degree of preferred orientation. The amount of 'order' in such states can be defined by an order parameter that describes ordering in liquid crystals (Nishiguchi et al., 2017). Currently available image analysis tools have capabilities that enable estimation of such order from microscopy images of cell walls.

\section{Spectroscopy}

The region of the electromagnetic spectrum from 0.1 to $10 \mathrm{THz}$ $\left(3.3-333.6 \mathrm{~cm}^{-1}\right)$ is described as the terahertz $(\mathrm{THz})$ region. $\mathrm{THz}$ spectroscopy has the ability to distinguish between samples with good and poor long-range order and thus can probe the crystallinity of materials (McIntosh et al., 2012). For THz radiation, crystalline materials present well-defined absorption peaks while amorphous phases present featureless spectra. It can differentiate between different crystalline phases as well (Strachan et al., 2005). THz-time domain spectroscopy (TDS) has been applied to determine the degree of crystallinity of microcrystalline cellulose samples (Vieira and Pasquini, 2014). Because $\mathrm{THz}$ radiation is responsible for long-range periodic vibrations in crystals, the absorption bands can be directly related to the degree of crystallinity of the sample. As such, the technique can selectively detect crystalline cellulose and holds promise for characterization of cellulose in native cell wall samples.
Atomic force microscopy-based infrared (AFM-IR) spectroscopy combines the spatial resolution of AFM with the chemical analysis capability of IR spectroscopy. It was developed to overcome the diffraction barrier limitation of IR spectroscopy and the inability of AFM to discriminate materials on the basis of chemical composition. The nanometer scale spatial resolution of AFM-IR allows IR microspectroscopy to investigate many life science problems like subcellular imaging and spectroscopy of bacterial and mammalian cells. Extension of this technique to plant cell wall studies may reveal important information about the spatial distribution of various cell wall components.

\section{CONCLUSION AND OUTLOOK}

Describing the structure of cellulose has direct implications on understanding the anisotropic growth and mechanics of plants, designing efficient biofuel conversion, and developing biomassbased products. Nevertheless, complete elucidation of the structure of cellulose and its interaction with matrix components has not been possible due to the complexity and heterogeneity of the cell wall and its variability from species to species. Ambiguity in the interpretation of structural characterization data obtained from different plant sources could sometimes be explained by a complimentary technique. For example, in the case of crystal parameters of native cellulose, the ambiguity in XRD results were resolved by NMR spectroscopy, which established the existence of two cellulose allomorphs, cellulose I $\alpha$ and I $\beta$.

Ambiguities can also be seen among results quantifying certain properties measured through different techniques. For example, there is a large mismatch between estimates of the lateral dimension of cellulose crystallites obtained from XRD and from electron microscopy. Most often, this mismatch is attributed to artifacts induced by sample preparation for electron microscopy. Due to the structural complexity, a single technique cannot characterize a cellulose microfibril completely. Recent reports present cell wall characterization through combined application of complementary techniques like diffraction, scattering, spectroscopy, and microscopy. This combination of techniques is also applied for examining the interaction between cellulose and other cell wall polysaccharides by either studying cellulose microfibrils after sequential removal of other polysaccharides (top-down approach) or by studying the effect on cellulose after introducing additives to bacterial cellulose composites (bottom-up approach). Recent developments in SSNMR have also enabled the study of interactions of cell wall components with each other and with water directly in native primary cell walls of plants.

The perpetual concern of introduction of artifacts during cell wall preparation has been reduced with the application of techniques like AFM and X-ray scattering that require minimal sample preparation. These approaches allow for the characterization of cell walls in near native states. The use of hybrid techniques like AFM-IR/Raman and advanced scattering techniques like RSoXS can provide chemical sensitivity along with high spatial resolution. In addition, use of advanced 
microscopic techniques like cryogenic electron tomography (cryo-ET) can create 3D reconstructions of nearly native cell walls and use of image analysis tools can quantify aspects of the microstructure.

Despite tremendous progress to date, many aspects of cellulose structure, and cellulose-cellulose and cellulose-matrix interactions are not well understood. The relation between the nanostructure of the cell wall and its macroscopic properties remains elusive. The current model of the primary cell wall suggests the existence of 'biomechanical hotspots', which are sites of close contacts between cellulose microfibrils mediated by xyloglucans (Cosgrove, 2014). These are proposed as the control sites for wall extension. Nevertheless, many questions regarding the creation, destruction, location, and functioning mechanism of these structures are yet to be answered. Furthermore, recent work shows a linear correlation between the FWHM of cellulose (200) diffraction peaks and $d$-spacing for different sources (Huang et al., 2018). Thus, the $d$-spacing of cellulose is inversely proportional to the crystallite size. This inverse proportionality might be from enhanced thermal fluctuations and higher para-crystalline disorder in smaller crystals; yet, further work is warranted to ascertain the origin of this empirical relationship. We predict that the application of emerging approaches and multi-modal analyses (combination of multiple techniques) will generate

\section{REFERENCES}

Abe, H., Funada, R., Ohtani, J., and Fukazawa, K. (1997). Changes in the arrangement of cellulose microfibrils associated with the cessation of cell expansion in tracheids. Trees 11, 328-332. doi: 10.1007/s0046800 50092

Ade, H., and Hitchcock, A. P. (2008). NEXAFS microscopy and resonant scattering: composition and orientation probed in real and reciprocal space. Polymer 49, 643-675. doi: 10.1016/j.polymer.2007.10.030

Agarwal, U. P. (2014). 1064 nm FT-Raman spectroscopy for investigations of plant cell walls and other biomass materials. Front. Plant Sci. 5:490. doi: 10.3389/fpls. 2014.00490

Agarwal, U. P., Reiner, R. R., and Ralph, S. A. (2013). Estimation of cellulose crystallinity of lignocelluloses using near-IR FT-raman spectroscopy and comparison of the raman and segal-WAXS methods. J. Agric. Food Chem. 61, 103-113. doi: 10.1021/jf304465k

Agarwal, U. P., Reiner, R. S., and Ralph, S. A. (2010). Cellulose I crystallinity determination using FT-Raman spectroscopy: univariate and multivariate methods. Cellulose 17, 721-733. doi: 10.1007/s10570-010-9420-z

Ahmed, A. U., Ahmed, N., Aslam, J., Butt, N. M., Khan, Q. H., and Atta, M. A. (1976). Neutron diffraction studies of the unit cell of cellulose II. J. Polym. Sci. 14, 561-564. doi: 10.1002/pol.1976.130140909

Ahvenainen, P., Kontro, I., and Svedström, K. (2016). Comparison of sample crystallinity determination methods by X-ray diffraction for challenging cellulose I materials. Cellulose 23, 1073-1086. doi: 10.1007/s10570-016-0881-6

Altaner, C. M., and Jarvis, M. C. (2008). Modelling polymer interactions of the 'molecular Velcro' type in wood under mechanical stress. J. Theor. Biol. 253, 434-445. doi: 10.1016/j.jtbi.2008.03.010

Amiri, H., and Karimi, K. (2015). Improvement of acetone, butanol, and ethanol production from woody biomass using organosolv pretreatment. Bioprocess Biosyst. Eng. 38, 1959-1972. doi: 10.1007/s00449-015-1437-0

Anderson, C. T., Carroll, A., Akhmetova, L., and Somerville, C. (2010). Real-time imaging of cellulose reorientation during cell wall expansion in arabidopsis roots. Plant Physiol. 152, 787-796. doi: 10.1104/pp.109.150128

Andersson, S., Serimaa, R., Torkkeli, M., Paakkari, T., Saranpää, P., and Pesonen, E. (2000). Microfibril angle of Norway spruce [Picea abies (L.) Karst.] compression new insights on the abovementioned topics and on other open questions regarding the regulation of cell wall growth and mechanics.

\section{AUTHOR CONTRIBUTIONS}

EWG, EDG, DY, and SR contributed to the conception and design of the review. All authors wrote the manuscript, contributed to manuscript revisions, and read and approved the submitted version.

\section{FUNDING}

This work was supported as part of the Center for Lignocellulose Structure and Formation, an Energy Frontier Research Center funded by the United States Department of Energy, Office of Science, Basic Energy Sciences under award no. DE-SC0001090.

\section{ACKNOWLEDGMENTS}

The authors acknowledge Dan Cosgrove for educational discussions.

wood: comparison of measuring techniques. J. Wood Sci. 46, 343-349. doi: 10.1007/BF00776394

Araujo, C., Freire, C. S. R., Nolasco, M. M., Ribeiro-Claro, P. J. A., Rudić, S., Silvestre, A. J. D., et al. (2018). Hydrogen bond dynamics of cellulose through inelastic neutron scattering spectroscopy. Biomacromolecules 19, 1305-1313. doi: 10.1021/acs.biomac.8b00110

Astley, O. M., Chanliaud, E., Donald, A. M., and Gidley, M. J. (2001). Structure of Acetobacter cellulose composites in the hydrated state. Int. J. Biol. Macromol. 29, 193-202. doi: 10.1016/S0141-8130(01)00167-2

Astley, O. M., and Donald, A. M. (2001). A small-angle X-ray scattering study of the effect of hydration on the microstructure of flax fibers. Biomacromolecules 2, 672-680. doi: 10.1021/bm0056431

Atalla, R. H. (1987). "Structures of Cellulose," in The Structures of Cellulose, ed. R. H. Atalla, (Washington, DC: American Chemical Society), 1-14. doi: 10. 1021/bk-1987-0340

Atalla, R. H., and Vanderhart, D. L. (1984). Native cellulose: a composite of two distinct crystalline forms. Science 223, 283-285. doi: 10.1126/science.223. 4633.283

Atalla, R. H., and VanderHart, D. L. (1999). The role of solid state 13C NMR spectroscopy in studies of the nature of native celluloses. Solid State Nuclear Magn. Reson. 15, 1-19. doi: 10.1016/S0926-2040(99)00042-9

Awano, T., Takabe, K., and Fujita, M. (2002). Xylan deposition on secondary wall of Fagus crenata fiber. Protoplasma 219, 106-115. doi: 10.1007/s00709020 0011

Axelrod, D. (2001). Total internal reflection fluorescence microscopy in cell biology. Traffic 2, 764-774. doi: 10.1034/j.1600-0854.2001.21104.x

Bailey, I. W., and Vestal, M. R. (1937). The orientation of cellulose in the secondary wall of tracheary cells. J. Arnold Arbor. 18, 185-195. doi: 10.1104/pp.17. 00885

Baker, J. L., Jimison, L. H., Mannsfeld, S., Volkman, S., Yin, S., Subramanian, V., et al. (2010). Quantification of thin film crystallographic orientation using $\mathrm{X}$-ray diffraction with an area detector. Langmuir 26, 9146-9151. doi: 10.1021/ la904840q

Bali, G., Foston, M. B., O’Neill, H. M., Evans, B. R., He, J., and Ragauskas, A. J. (2013). The effect of deuteration on the structure of bacterial cellulose. Carbohydr. Res. 374, 82-88. doi: 10.1016/j.carres.2013.04.009 
Barnett, J. R., and Bonham, V. A. (2007). Cellulose microfibril angle in the cell wall of wood fibres. Biol. Rev. 79, 461-472. doi: 10.1017/S14647931030 06377

Barnette, A. L., Lee, C., Bradley, L. C., Schreiner, E. P., Park, Y. B., Shin, H., et al. (2012). Quantification of crystalline cellulose in lignocellulosic biomass using sum frequency generation (SFG) vibration spectroscopy and comparison with other analytical methods. Carbohydr. Polym. 89, 802-809. doi: 10.1016/j. carbpol.2012.04.014

Bartesaghi, A., Merk, A., Banerjee, S., Matthies, D., Wu, X., Milne, J. L. S., et al. (2015). 2.2 A resolution cryo-EM structure of $\beta$-galactosidase in complex with a cell-permeant inhibitor. Science 348, 1147-1151. doi: 10.1126/science.aab1576

Bayley, S. T., Colvin, J. R., Cooper, F. P., and Martin-Smith, C. A. (1957). The structure of the primary epidermal cell wall of avena coleoptiles. J. Biophys. Biochem. Cytol. 3, 171-182. doi: 10.1083/jcb.3.2.171

Beer, M., and Setterfield, G. (1958). Fine structure in thickened primary walls of collenchyma cells of celery petioles. Am. J. Bot. 45, 571-580. doi: 10.1002/j. 1537-2197.1958.tb13169.x

Beg, M. M., Aslam, J., Khan, Q. H., Butt, N. M., Rolandson, S., and Ahmed, A. U. (1974). Neutron diffraction studies of the unit cell of cellulose I. J. Polym. Sci. 12, 311-318. doi: 10.1002/pol.1974.130120602

Bergander, A., and Salmén, L. (2002). Cell wall properties and their effects on the mechanical properties of fibers. J. Mater. Sci. 37, 151-156. doi: 10.1023/A: 1013115925679

Bootten, T. J., Harris, P. J., Melton, L. D., and Newman, R. H. (2004). Solid-state 13C-NMR spectroscopy shows that the xyloglucans in the primary cell walls of mung bean (Vigna radiata L.) occur in different domains: a new model for xyloglucan-cellulose interactions in the cell wall. J. Exp. Bot. 55, 571-583. doi: 10.1093/jxb/erh065

Bossi, M., Fölling, J., Belov, V. N., Boyarskiy, V. P., Medda, R., Egner, A., et al. (2008). Multicolor far-field fluorescence nanoscopy through isolated detection of distinct molecular species. Nano Lett. 8, 2463-2468. doi: 10.1021/nl801471d

Boudaoud, A., Burian, A., Borowska-Wykręt, D., Uyttewaal, M., Wrzalik, R., Kwiatkowska, D., et al. (2014). FibrilTool, an ImageJ plug-in to quantify fibrillar structures in raw microscopy images. Nat. Protoc. 9, 457-463. doi: 10.1038/ nprot.2014.024

Bourret, A., Chanzy, H., and Lazaro, R. (1972). Crystallite features of valonia cellulose by electron diffraction and dark-field electron microscopy. Biopolymers 11, 893-898. doi: 10.1002/bip.1972.3601 10412

Boyd, J. D., and Foster, R. C. (1974). Tracheid anatomy changes as responses to changing structural requirements of the tree. Wood Sci. Technol. 8, 91-105. doi: 10.1007/BF00351365

Brunecky, R., Vinzant Todd, B., Porter Stephanie, E., Donohoe Bryon, S., Johnson David, K., and Himmel Michael, E. (2008). Redistribution of xylan in maize cell walls during dilute acid pretreatment. Biotechnol. Bioeng. 102, 1537-1543. doi: 10.1002/bit.22211

Butt, H. J., Wolff, E. K., Gould, S. A. C., Dixon Northern, B., Peterson, C. M., and Hansma, P. K. (1990). Imaging cells with the atomic force microscope. J. Struct. Biol. 105, 54-61. doi: 10.1016/1047-8477(90)90098-W

Carpita, N. C., and Gibeaut, D. M. (1993). Structural models of primary cell walls in flowering plants: consistency of molecular structure with the physical properties of the walls during growth. Plant J. 3, 1-30. doi: 10.1111/j.1365-313X.1993. tb00007.x

Carpita, N. C., Marianne, D., Findlay, K., Wells, B., Shoue, D. A., Gareth, C., et al. (2001). Cell wall architecture of the elongating maize coleoptile. Plant Physiol. 127, 551-565. doi: 10.1104/pp.010146

Caulfield, D. F. (1971). Crystallite sizes in wet and dry Valonia ventricosa textile. Res. J. 41, 264-280.

Cave, I. D. (1968). The anisotropic elasticity of the plant cell wall. Wood Sci. Technol. 2, 268-278. doi: 10.1007/BF00350273

Chebli, Y., and Geitmann, A. (2017). Cellular growth in plants requires regulation of cell wall biochemistry. Curr. Opin. Cell Biol. 44, 28-35. doi: 10.1016/j.ceb. 2017.01.002

Cheng, G., Varanasi, P., Li, C., Liu, H., Melnichenko, Y. B., Simmons, B. A., et al. (2011). Transition of cellulose crystalline structure and surface morphology of biomass as a function of ionic liquid pretreatment and its relation to enzymatic hydrolysis. Biomacromolecules 12, 933-941. doi: 10.1021/bm101240z
Choong, F. X., Bäck, M., Steiner, S. E., Melican, K., Nilsson, K. P. R., Edlund, U., et al. (2016). Nondestructive, real-time determination and visualization of cellulose, hemicellulose and lignin by luminescent oligothiophenes. Sci. Rep. 6:35578. doi: 10.1038/srep35578

Chundawat, S. P. S., Donohoe, B. S., da Costa Sousa, L., Elder, T., Agarwal, U. P., Lu, F., et al. (2011). Multi-scale visualization and characterization of lignocellulosic plant cell wall deconstruction during thermochemical pretreatment. Energy Environ. Sci. 4, 973-984. doi: 10.1039/c0ee0 $0574 \mathrm{f}$

Cody, G. D. (2000). Probing chemistry within the membrane structure of wood with soft X-ray spectral microscopy. AIP Conf. Proc. 507, 307-312. doi: 10.1063/ 1.1291162

Cody, G. D., Brandes, J., Jacobsen, C., and Wirick, S. (2009). Soft X-ray induced chemical modification of polysaccharides in vascular plant cell walls. J. Electr. Spectrosc. Relat. Phenomena 170, 57-64. doi: 10.1016/j.elspec.2008. 09.007

Colvin, J. R. (1963). The size of the cellulose microfibril. J. Cell Biol. 17, 105-109. doi: $10.1083 /$ jcb.17.1.105

Cosgrove, D., and Jarvis, M. (2012). Comparative structure and biomechanics of plant primary and secondary cell walls. Front. Plant Sci. 3:204. doi: 10.3389/ fpls.2012.00204

Cosgrove, D. J. (2005). Growth of the plant cell wall. Nat. Rev. Mol. Cell Biol. 6, 850-861. doi: $10.1038 / \mathrm{nrm} 1746$

Cosgrove, D. J. (2014). Re-constructing our models of cellulose and primary cell wall assembly. Curr. Opin. Plant Biol. 22, 122-131. doi: 10.1016/j.pbi.2014. 11.001

Cox, G., and Juniper, B. (1973). Electron microscopy of cellulose in entire tissue. J. Microsc. 97, 343-355. doi: 10.1111/j.1365-2818.1973.tb03789.x

Crow, E., and Murphy, R. J. (2000). Microfibril orientation in differentiating and maturing fibre and parenchyma cell walls in culms of bamboo (Phyllostachys viridi-glaucescens (Carr.) Riv. \& Riv.). Bot. J. Linnean Soc. 134, 339-359. doi: 10.1111/j.1095-8339.2000.tb02357.x

Davies, L. M., and Harris, P. J. (2003). Atomic force microscopy of microfibrils in primary cell walls. Planta 217, 283-289.

De Figueiredo, L. P., and Ferreira, F. F. (2014). The rietveld method as a tool to quantify the amorphous amount of microcrystalline cellulose. J. Pharm. Sci. 103, 1394-1399. doi: 10.1002/jps.23909

Dellisanti, C. (2015). A barrier-breaking resolution. Nat. Struct. Mol. Biol. 22, 361-361. doi: 10.1038/nsmb.3025

Ding, S. Y., and Himmel, M. E. (2006). The maize primary cell wall microfibril: a new model derived from direct visualization. J. Agric. Food Chem. 54, 597-606. doi: $10.1021 /$ jf051851z

Ding, S.-Y., Zhao, S., and Zeng, Y. (2014). Size, shape, and arrangement of native cellulose fibrils in maize cell walls. Cellulose 21, 863-871. doi: 10.1007/s10570013-0147-5

Donaldson, L. (2008). Microfibril angle: measurement, variation and relationship: a review. IAWA J. 29, 387-396. doi: 10.1163/22941932-90000192

Donaldson, L., and Frankland, A. (2004). Ultrastructure of iodine treated wood. Holzforschung 58, 219-225. doi: 10.1515/HF.2004.034

Driemeier, C. (2014). Two-dimensional Rietveld analysis of celluloses from higher plants. Cellulose 21, 1065-1073. doi: 10.1007/s10570-013-9995-2

Dunning, C. E. (1968). Cell wall morphology of longleaf pine latewood. Wood Sci. Technol. 1, 65-76.

El-Hosseiny, F., and Page, D. H. (1973). The measurement of fibril angle of wood fibres using polarised light. Wood Fibre 5:7.

El-osta, M. L. M., Kellogg, R. M., Foschi, R. O., and Butters, R. G. (1973). A direct $\mathrm{x}$-ray technique for measuring microfibril angle. Wood Fibre 5, 118-128.

Erickson, H. D., and Arima, T. (1974). Douglas-fir wood quality studies Part II: effects of age and stimulated growth on fibril angle and chemical constituents. Wood Sci. Technol. 8, 255-265. doi: 10.1007/BF00351859

Fernandes, A. N., Thomas, L. H., Altaner, C. M., Callow, P., Forsyth, V. T., Apperley, D. C., et al. (2011). Nanostructure of cellulose microfibrils in spruce wood. Proc. Natl. Acad. Sci. U.S.A. 108, E1195-E1203. doi: 10.1073/pnas. 1108942108

Fragola, A., Aigouy, L., Mignotte, P. Y., Formanek, F., and De Wilde, Y. (2004). Apertureless scanning near-field fluorescence microscopy in liquids. Ultramicroscopy 101, 47-54. doi: 10.1016/j.ultramic.2004.04.002 
Frei, E. V. A., Preston, R. D., and Ripley, G. W. (1957). The fine structure of the walls of conifer tracheids: VI. Electron microscope investigations of sections. J. Exp. Bot. 8, 139-146. doi: 10.1093/jxb/8.1.139

French, A. D., Roughead, W. A., and Miller, D. P. (1987). "X-ray diffraction studies of ramie cellulose I," in The Structures of Cellulose, ed. R. H. Atalla (Washington, DC: American Chemical Society), 15-37.

Frilette, V. J., Hanle, J., and Mark, H. (1948). Rate of exchange of cellulose with heavy water. J. Am. Chem. Soc. 70, 1107-1113. doi: 10.1021/ja01183a071

Fu, Y., Winter, P. W., Rojas, R., Wang, V., McAuliffe, M., and Patterson, G. H. (2016). Axial superresolution via multiangle TIRF microscopy with sequential imaging and photobleaching. Proc. Natl. Acad. Sci. U.S.A. 113, 4368-4373. doi: $10.1073 /$ pnas. 1516715113

Gilbert, H. J., Knox, J. P., and Boraston, A. B. (2013). Advances in understanding the molecular basis of plant cell wall polysaccharide recognition by carbohydrate-binding modules. Curr. Opin. Struct. Biol. 23, 669-677. doi: 10.1016/j.sbi.2013.05.005

Gomez, E. D., Barteau, K. P., Wang, H., Toney, M. F., and Loo, Y.-L. (2011). Correlating the scattered intensities of P3HT and PCBM to the current densities of polymer solar cells. Chem. Commun. 47, 436-438. doi: 10.1039/c0cc02927k

$\mathrm{Gu}$, J., and Catchmark, J. M. (2012). Impact of hemicelluloses and pectin on sphere-like bacterial cellulose assembly. Carbohydr. Polym. 88, 547-557. doi: 10.1016/j.carbpol.2011.12.040

Gunning, A. P., Kirby, A. R., Morris, V. J., Wells, B., and Brooker, B. E. (1995). Imaging bacterial polysaccharides by AFM. Polym. Bull. 34, 615-619. doi: 10. 1007/BF00423359

Guo, C., Kozub, D. R., Kesava, S. V., Wang, C., Hexemer, A., and Gomez, E. D. (2013). Signatures of multiphase formation in the active layer of organic solar cells from resonant soft X-ray scattering. ACS Macro Lett. 2, 185-189. doi: $10.1021 / \mathrm{mz} 300547 \mathrm{x}$

Gusev, G. V. (1978). Hermans-Weidinger X-ray diffraction technique for determining polymer crystallinity and the use of the Ruland ratio. Polym. Sci. U.S.S.R. 20, 1295-1297. doi: 10.1016/0032-3950(78)90270-8

Ha, M. A., Apperley, D. C., Evans, B. W., Huxham, I. M., Jardine, W. G., Viëtor, R. J., et al. (1998). Fine structure in cellulose microfibrils: NMR evidence from onion and quince. Plant J. 16, 183-190. doi: 10.1046/j.1365-313x.1998.00291.x

Harris, D., Bulone, V., Ding, S.-Y., and DeBolt, S. (2010). Tools for cellulose analysis in plant cell walls. Plant Physiol. 153, 420-426. doi: 10.1104/pp.110. 154203

Harris, D. M., Corbin, K., Wang, T., Gutierrez, R., Bertolo, A. L., Petti, C., et al. (2012). Cellulose microfibril crystallinity is reduced by mutating C-terminal transmembrane region residues CESA1A903V and CESA3T942I of cellulose synthase. Proc. Natl. Acad. Sci. U.S.A. 109, 4098-4103. doi: 10.1073/pnas. 1200352109

Hayashi, T., and Maclachlan, G. (1984). Pea xyloglucan and cellulose. Plant Physiol. 75, 596-604. doi: 10.1104/pp.75.3.596

He, J., Pingali, S. V., Chundawat, S. P. S., Pack, A., Jones, A. D., Langan, P., et al. (2014). Controlled incorporation of deuterium into bacterial cellulose. Cellulose 21, 927-936. doi: 10.1016/bs.mie.2015.08.031

Helbert, W., Nishiyama, Y., Okano, T., and Sugiyama, J. (1998a). Molecular imaging of Halocynthia papillosa cellulose. J. Struct. Biol. 124, 42-50.

Helbert, W., Sugiyama, J., Kimura, S., and Itoh, T. (1998b). High-resolution electron microscopy on ultrathin sections of cellulose microfibrils generated by glomerulocytes in Polyzoa vesiculiphora. Protoplasma 203, 84-90. doi: 10.1007/ BF01280590

Hessler, L. E., and Power, R. E. (1954). The use of iodine adsorption as a measure of cellulose fiber crystallinity. Textile Res. J. 24, 822-827. doi: 10.1177/ 004051755402400906

Heyn, A. N. J. (1955). Small particle X-ray scattering by fibers, size and shape of microcrystallites. J. Appl. Phys. 26, 519-526. doi: 10.1063/1.1722032

Heyn, A. N. J. (1966). The microcrystalline structure of cellulose in cell walls of cotton, ramie, and jute fibers as revealed by negative staining of sections. J. Cell Biol. 29, 181-197. doi: 10.1083/jcb.29.2.181

Hill, J. L., Hammudi, M. B., and Tien, M. (2014). The Arabidopsis cellulose synthase complex: a proposed hexamer of CESA trimers in an equimolar stoichiometry. Plant Cell 26, 4834-4842. doi: 10.1105/tpc.114.131193

Hiller, C. H. (1964). Correlation of fibril angle with wall thickness of tracheids in summerwood of slash und loblolly pine. Tappi 47, 125-128.
Himmel, M. E., Ding, S.-Y., Johnson, D. K., Adney, W. S., Nimlos, M. R., Brady, J. W., et al. (2007). Biomass recalcitrance: engineering plants and enzymes for biofuels production. Science 315, 804-807. doi: 10.1126/science. 1137016

Hindeleh, A. M., and Johnson, D. J. (1972). Crystallinity and crystallite size measurement in cellulose fibres: 1. Ramie and Fortisan. Polymer 13, 423-430. doi: 10.1016/0032-3861(72)90107-3

Hindeleh, A. M., and Johnson, D. J. (1974). Crystallinity and crystallite size measurement in cellulose fibres: 2. Viscose rayon. Polymer 15, 697-705. doi: 10.1016/0032-3861(74)90020-2

Hofstetter, K., Hellmich, C., and Eberhardsteiner, J. (2005). Development and experimental validation of a continuum micromechanics model for the elasticity of wood. Eur. J. Mech. 24, 1030-1053. doi: 10.1016/j.euromechsol. 2005.05.006

Holt, C., Mackie, W., and Sellen, D. B. (1973). Degree of polymerization and polydis-persity of native cellulose. J. Polym. Sci. 42, 1505-1512. doi: 10.1002/ polc. 5070420353

Honjo, G., and Watanabe, M. (1958). Examination of cellulose fibre by the lowtemperature specimen method of electron diffraction and electron microscopy. Nature 181, 326-328. doi: 10.1038/181326a0

Horikawa, Y., Clair, B., and Sugiyama, J. (2009). Varietal difference in cellulose microfibril dimensions observed by infrared spectroscopy. Cellulose 16, 1-8. doi: 10.1007/s10570-008-9252-2

Howsmon, J. A. (1949). Water sorption and the poly-phase structure of cellulose fibers. Textile Res. J. 19, 152-162. doi: 10.1177/004051754901900303

Huang, B., Bates, M., and Zhuang, X. (2009). Super resolution fluorescence microscopy. Annu. Rev. Biochem. 78, 993-1016. doi: 10.1146/annurev.biochem. 77.061906.092014

Huang, B., Wang, W., Bates, M., and Zhuang, X. (2008). Three-dimensional superresolution imaging by stochastic optical reconstruction microscopy. Science 319, 810-813. doi: 10.1126/science.1153529

Huang, S., Makarem, M., Kiemle, S. N., Zheng, Y., He, X., Ye, D., et al. (2018). Dehydration-induced physical strains of cellulose microfibrils in plant cell walls. Carbohydr. Polym. 197, 337-348. doi: 10.1016/j.carbpol.2018.05.091

Ingham, B., Erlangga, G. D., Smialowska, A., Kirby, N. M., Wang, C., MatiaMerino, L., et al. (2015). Solving the mystery of the internal structure of casein micelles. Soft Matter 11, 2723-2725. doi: 10.1039/c5sm00153f

Ingham, B., Smialowska, A., Erlangga, G. D., Matia-Merino, L., Kirby, N. M., Wang, C., et al. (2016). Revisiting the interpretation of casein micelle SAXS data. Soft Matter 12, 6937-6953. doi: 10.1039/c6sm01091a

Inouye, H., Zhang, Y., Yang, L., Venugopalan, N., Fischetti, R. F., Gleber, S. C., et al. (2014). Multiscale deconstruction of molecular architecture in corn stover. Sci. Rep. 4:3756. doi: 10.1038/srep03756

Ioelovich, M. (2016). Physicochemical methods for determination of cellulose crystallinity. ChemXpress 9, 245-251.

Isogai, A., Usuda, M., Kato, T., Uryu, T., and Atalla, R. H. (1989). Solid-state CP/MAS carbon-13 NMR study of cellulose polymorphs. Macromolecules 22, 3168-3172. doi: 10.1021/ma00197a045

Jakob, H. F., Fengel, D., Tschegg, S. E., and Fratzl, P. (1995). The elementary cellulose fibril in picea abies: comparison of transmission electron microscopy, small-angle $\mathrm{X}$-ray scattering, and wide-angle $\mathrm{X}$-ray scattering results. Macromolecules 28, 8782-8787. doi: 10.1021/ma00130a010

Jakob, H. F., Fratzl, P., and Tschegg, S. E. (1994). Size and arrangement of elementary cellulose fibrils in wood cells: a small-angle X-ray scattering study of Picea abies. J. Struct. Biol. 113, 13-22. doi: 10.1006/jsbi.1994.1028

Jakob, H. F., Tschegg, S. E., and Fratzl, P. (1996). Hydration dependence of the wood-cell wall structure in Picea abies. A small-angle X-ray scattering study. Macromolecules 29, 8435-8440. doi: 10.1021/ma9605661

Johnson, A., and Vert, G. (2017). Single event resolution of plant plasma membrane protein endocytosis by tirf microscopy. Front. Plant Sci. 8:612. doi: 10.3389/fpls. 2017.00612

Jones, P. D., Schimleck, L. R., Peter, G. F., Daniels, R. F., and Clark, A. (2005). Nondestructive estimation of Pinus taeda L. wood properties for samples from a wide range of sites in Georgia. Can. J. Forest Res. 35, 85-92. doi: 10.1139/x04160

Jordan, B. M., and Dumais, J. (2010). Biomechanics of Plant Cell Growth. Encyclopedia of Life Sciences. Hoboken, NJ: Wiley. 
Ju, X., Bowden, M., Brown, E. E., and Zhang, X. (2015). An improved X-ray diffraction method for cellulose crystallinity measurement. Carbohydr. Polym. 123, 476-481. doi: 10.1016/j.carbpol.2014.12.071

Jungnikl, K., Paris, O., Fratzl, P., and Burgert, I. (2007). The implication of chemical extraction treatments on the cell wall nanostructure of softwood. Cellulose 15:407. doi: 10.1007/s10570-007-9181-5

Kafle, K., Xi, X., Lee, C. M., Tittmann, B. R., Cosgrove, D. J., Park, Y. B., et al. (2014). Cellulose microfibril orientation in onion (Allium cepa L.) epidermis studied by atomic force microscopy (AFM) and vibrational sum frequency generation (SFG) spectroscopy. Cellulose 21, 1075-1086. doi: 10.1007/s10570-013-0121-2

Kantola, M., and Kähkönen, H. (1963). Small-angle X-ray investigation of the orientation of crystallites in Finnish coniferous and deciduous wood fibres. Ann. Acad. Sci. Fenn. 137:14.

Kantola, M., and Seitsonen, S. (1961). X-ray orientation investigations on finish conifers. Ann. Acad. Scient. Fenn. 80, 1-15.

Karimi, K., and Taherzadeh, M. J. (2016). A critical review of analytical methods in pretreatment of lignocelluloses: composition, imaging, and crystallinity. Bioresour. Technol. 200, 1008-1018. doi: 10.1016/j.biortech.2015.11.022

Kawakubo, T., Karita, S., Araki, Y., Watanabe, S., Oyadomari, M., Takada, R., et al. (2009). Analysis of exposed cellulose surfaces in pretreated wood biomass using carbohydrate-binding module (CBM)-cyan fluorescent protein (CFP). Biotechnol. Bioeng. 105, 499-508. doi: 10.1002/bit.22550

Kennedy, C. J., Cameron, G. J., Šturcová, A., Apperley, D. C., Altaner, C., Wess, T. J., et al. (2007a). Microfibril diameter in celery collenchyma cellulose: X-ray scattering and NMR evidence. Cellulose 14, 235-246. doi: 10.1007/s10570-0079116-1

Kennedy, C. J., Šturcová, A., Jarvis, M. C., and Wess, T. J. (2007b). Hydration effects on spacing of primary-wall cellulose microfibrils: a small angle X-ray scattering study. Cellulose 14, 401-408. doi: 10.1007/s10570-007-9129-9

Kent, M. S., Cheng, G., Murton, J. K., Carles, E. L., Dibble, D. C., Zendejas, F., et al. (2010). Study of enzymatic digestion of cellulose by small angle neutron scattering. Biomacromolecules 11, 357-368. doi: 10.1021/bm9008952

Kim, J. S., Awano, T., Yoshinaga, A., and Takabe, K. (2012). Ultrastructure of the innermost surface of differentiating normal and compression wood tracheids as revealed by field emission scanning electron microscopy. Planta 235, 12091219. doi: $10.1007 / \mathrm{s} 00425-011-1569-7$

Kim, S. H., Lee, C. M., and Kafle, K. (2013). Characterization of crystalline cellulose in biomass: basic principles, applications, and limitations of XRD, NMR, IR, Raman, and SFG. Korean J. Chem. Eng 30, 2127-2141. doi: 10.1007/s11814013-0162-0

Kirby, A. R., Gunning, A. P., Waldron, K. W., Morris, V. J., and Ng, A. (1996). Visualization of plant cell walls by atomic force microscopy. Biophys. J. 70, 1138-1143. doi: 10.1016/S0006-3495(96)79708-4

Kirby, A. R., Ng, A., Waldron, K. W., and Morris, V. J. (2006). AFM investigations of cellulose fibers in bintje potato (Solanum tuberosum L.) cell wall fragments. Food Biophys. 1, 163-167. doi: 10.1007/s11483-006-9013-4

Kljun, A., Benians, T. A. S., Goubet, F., Meulewaeter, F., Knox, J. P., and Blackburn, R. S. (2011). Comparative analysis of crystallinity changes in cellulose I polymers using ATR-FTIR, X-ray diffraction, and carbohydratebinding module probes. Biomacromolecules 12, 4121-4126. doi: 10.1021/ bm201176m

Koyama, M., Helbert, W., Imai, T., Sugiyama, J., and Henrissat, B. (1997). Parallelup structure evidences the molecular directionality during biosynthesis of bacterial cellulose. Proc. Natl. Acad. Sci. U.S.A. 94, 9091-9095. doi: 10.1073/ pnas.94.17.9091

Kraissig, H. A. (1992). "Fibrillar Structure," in Cellulose: Structure, Accessibility and Reactivity, ed. M. B. Huglin (Yverdon -les-Bains: Gordon and Breach Science Publishers).

Kubicki, J. D., Yang, H., Sawada, D., O’Neill, H., Oehme, D., and Cosgrove, D. (2018). The shape of native plant cellulose microfibrils. Sci. Rep. 8:13983. doi: 10.1038/s41598-018-32211-w

Kuga, S., and Brown, R. M. Jr. (1987a). Lattice imaging of ramie cellulose. Polym. Commun. 28, 311-314.

Kuga, S., and Brown, R. M. (1987b). Practical aspects of lattice imaging of cellulose. J. Electr. Microsc. Techn. 6, 349-356. doi: 10.1002/jemt.1060060405

Kumar, M., and Turner, S. (2015). Protocol: a medium-throughput method for determination of cellulose content from single stem pieces of Arabidopsis thaliana. Plant Methods 11:46. doi: 10.1186/s13007-015-0090-6
Lawrence, J. R., Swerhone, G. D. W., Leppard, G. G., Araki, T., Zhang, X., West, M. M., et al. (2003). Scanning transmission X-ray, laser scanning, and transmission electron microscopy mapping of the exopolymeric matrix of microbial biofilms. Appl. Environ. Microbiol. 69, 5543-5554. doi: 10.1128/AEM. 69.9.5543-5554.2003

Lee, C. M., Kafle, K., Belias, D. W., Park, Y. B., Glick, R. E., Haigler, C. H., et al. (2015a). Comprehensive analysis of cellulose content, crystallinity, and lateral packing in Gossypium hirsutum and Gossypium barbadense cotton fibers using sum frequency generation, infrared and Raman spectroscopy, and X-ray diffraction. Cellulose 22, 971-989. doi: 10.1007/s10570-0140535-5

Lee, C. M., Kubicki, J. D., Fan, B., Zhong, L., Jarvis, M. C., and Kim, S. H. (2015b). Hydrogen-bonding network and $\mathrm{OH}$ stretch vibration of cellulose: comparison of computational modeling with polarized IR and SFG Spectra. J. Phys. Chem. B 119, 15138-15149. doi: 10.1021/acs.jpcb.5b08015

Lee, C. M., Kafle, K., Park, Y. B., and Kim, S. H. (2014). Probing crystal structure and mesoscale assembly of cellulose microfibrils in plant cell walls, tunicate tests, and bacterial films using vibrational Sum Frequency Generation (SFG) spectroscopy. Phys. Chem. Chem. Phys. 16, 10844-10853. doi: 10.1039/ c4cp00515e

Lee, C. M., Mittal, A., Barnette, A. L., Kafle, K., Park, Y. B., Shin, H., et al. (2013). Cellulose polymorphism study with sum-frequency-generation (SFG) vibration spectroscopy: identification of exocyclic $\mathrm{CH} 2 \mathrm{OH}$ conformation and chain orientation. Cellulose 20, 991-1000. doi: 10.1007/s10570-0139917-3

Levi, M. P., and Sellen, D. B. (1967). The degree-of-polymerization and polydispersity of cellulose in beechwood, and its radial variation across fibre cell-walls. Carbohydr. Res. 5, 351-355. doi: 10.1016/S0008-6215(00)80513-3

Lichtenegger, H., Muller, M., Paris, O., Riekel, C., and Fratzl, P. (1999). Imaging of the helical arrangement of cellulose fibrils in wood by synchrotron X-ray microdiffraction. J. Appl. Crystallogr. 32, 1127-1133. doi: 10.1107/ S0021889899010961

Lionetto, F., Del Sole, R., Cannoletta, D., Vasapollo, G., and Maffezzoli, A. (2012). Monitoring wood degradation during weathering by cellulose crystallinity. Materials 5, 1910-1922. doi: 10.3390/ma5101910

Liu, F., Brady, M. A., and Wang, C. (2016). Resonant soft X-ray scattering for polymer materials. Eur. Polym. J. 81, 555-568. doi: 10.1016/j.eurpolymj.2016. 04.014

Maeva, E., Severin, F., Miyasaka, C., Tittmann, B. R., and Maev, R. G. (2009). Acoustic imaging of thick biological tissue. IEEE Trans. Ultrason. Ferroelectr. Freq. Control 56, 1352-1358. doi: 10.1109/TUFFC.2009.1191

Magazù, S., and Migliardo, F. (2011). Dynamics of Biological Macromolecules by Neutron Scattering. Emirate of Sharjah: Bentham Science Publishers.

Makarem, M., Sawada, D., O’Neill, H. M., Lee, C. M., Kafle, K., Park, Y. B., et al. (2017). Dependence of Sum Frequency Generation (SFG) spectral features on the mesoscale arrangement of SFG-active crystalline domains interspersed in SFG-inactive matrix: a case study with cellulose in uniaxially aligned control samples and alkali-treated secondary cell walls of plants. J. Phys. Chem. C 121, 10249-10257. doi: 10.1021/acs.jpcc.7b02770

Mancosky, D. G., Lucia, L. A., Nanko, H., Wirick, S., Rudie, A. W., and Braun, R. (2005). Novel visualization studies of lignocellulosic oxidation chemistry by application of C-near edge X-ray absorption fine structure spectroscopy. Cellulose 12, 35-41. doi: 10.1023/B:CELL.0000049352.60007.76

Manley, R. S. J. (2003). Molecular morphology of cellulose. J. Polym. Sci. Part A-2 Polym. Phys. 9, 1025-1059. doi: 10.1002/pol.1971.160090604

Mansfield, S. D., and Meder, R. (2003). Cellulose hydrolysis - the role of monocomponent cellulases in crystalline cellulose degradation. Cellulose 10, 159-169. doi: 10.1023/A:1024022710366

Marga, F., Grandbois, M., Cosgrove, D. J., and Baskin, T. I. (2005). Cell wall extension results in the coordinate separation of parallel microfibrils: evidence from scanning electron microscopy and atomic force microscopy. Plant J. 43, 181-190. doi: 10.1111/j.1365-313X.2005.02447.x

Mark, R. E. (1967). Cell Wall Mechanics of Tracheids. New Haven, CT: Yale University Press.

Martínez-Sanz, M., Gidley, M. J., and Gilbert, E. P. (2015a). Application of $\mathrm{X}$-ray and neutron small angle scattering techniques to study the hierarchical structure of plant cell walls: a review. Carbohydr. Polym. 125, 120-134. doi: 10.1016/j.carbpol.2015.02.010 
Martínez-Sanz, M., Lopez-Sanchez, P., Gidley, M. J., and Gilbert, E. P. (2015b). Evidence for differential interaction mechanism of plant cell wall matrix polysaccharides in hierarchically-structured bacterial cellulose. Cellulose 22, 1541-1563. doi: 10.1007/s10570-015-0614-2

Matias, V. R. F., and Beveridge, T. J. (2006). Native cell wall organization shown by cryo-electron microscopy confirms the existence of a periplasmic space in Staphylococcus aureus. J. Bacteriol. 188, 1011-1021. doi: 10.1128/JB.188.3.10111021.2006

Mattheyses, A. L., Simon, S. M., and Rappoport, J. Z. (2010). Imaging with total internal reflection fluorescence microscopy for the cell biologist. J. Cell Sci. 123, 3621-3628. doi: 10.1242/jcs.056218

McCann, M. C., Wells, B., and Roberts, K. (1990). Direct visualization of cross-links in the primary plant cell wall. J. Cell Sci. 96, 323-334.

McIntosh, A. I., Yang, B., Goldup, S. M., Watkinson, M., and Donnan, R. S. (2012). Terahertz spectroscopy: a powerful new tool for the chemical sciences? Chem Soc. Rev. 41, 2072-2082. doi: 10.1039/c1cs15277g

Mühlethaler, K. (1950). Electron microscopy of developing plant cell walls. Biochim. Biophys. Acta 5, 1-9. doi: 10.1016/0006-3002(50)90143-0

Müller, M., Czihak, C., Vogl, G., Fratzl, P., Schober, H., and Riekel, C. (1998). Direct observation of microfibril arrangement in a single native cellulose fiber by microbeam small-angle X-ray scattering. Macromolecules 31, 3953-3957. doi: $10.1021 / \mathrm{ma} 980004 \mathrm{c}$

Müller, M., Hori, R., Itoh, T., and Sugiyama, J. (2002). X-ray microbeam and electron diffraction experiments on developing xylem cell walls. Biomacromolecules 3, 182-186. doi: 10.1021/bm015605h

Müller, M., Riekel, C., Vuong, R., and Chanzy, H. (2000). Skin/core microstructure in viscose rayon fibres analysed by X-ray microbeam and electron diffraction mapping. Polymer 41, 2627-2632. doi: 10.1016/S0032-3861(99) 00433-4

Nelmes, B. J., and Preston, R. D. (1968). Cellulose microfibril orientation in rubbery wood. J. Exp. Bot. 19, 519-525. doi: 10.1093/jxb/19.3.519

Nelson, M. L., and O'Connor, R. T. (1964). Relation of certain infrared bands to cellulose crystallinity and crystal lattice type. Part II. A new infrared ratio for estimation of crystallinity in celluloses I and II. J. Appl. Polym. Sci. 8, 1325-1341. doi: 10.1002/app.1964.070080323

Newman, R. H. (1999). Estimation of the lateral dimensions of cellulose crystallites using 13C NMR signal strengths. Solid State Nuclear Magn. Reson. 15, 21-29. doi: 10.1016/S0926-2040(99)00043-0

Newman, R. H., and Hemmingson, J. A. (1990). Determination of the degree of cellulose crystallinity in wood by carbon-13 nuclear magnetic resonance spectroscopy. Holzforschung 44, 351-355. doi: 10.1515/hfsg.1990.44.5.351

Newman, R. H., Hemmingson, J. A., and Suckling, I. D. (1993). Carbon-13 nuclear magnetic resonance studies of kraft pulping. Holzforschung 47, 234-238. doi: 10.1515/hfsg.1993.47.3.234

Newman, R. H., Hill, S. J., and Harris, P. J. (2013). Wide-Angle X-Ray scattering and solid-state nuclear magnetic resonance data combined to test models for cellulose microfibrils in mung bean cell walls. Plant Physiol. 163, 1558-1567. doi: $10.1104 /$ pp.113.228262

Nieduszynski, I., and Preston, R. D. (1970). Crystallite size in natural cellulose. Nature 225, 273-274. doi: 10.1038/225273a0

Nishiguchi, D., Nagai, K. H., Chaté, H., and Sano, M. (2017). Long-range nematic order and anomalous fluctuations in suspensions of swimming filamentous bacteria. Phys. Rev. E 95:020601. doi: 10.1103/PhysRevE.95.020601

Nishikawa, S., and Ono, S. (1913). Transmission of X-rays through fibrous, lamellar and granular substances. Proc. Tokyo Math. Phys. Soc. 7, 131-138.

Nishiyama, Y., Langan, P., and Chanzy, H. (2002). Crystal structure and hydrogen-bonding system in cellulose $\mathrm{I} \beta$ from synchrotron X-ray and neutron fiber diffraction. J. Am. Chem. Soc. 124, 9074-9082. doi: 10.1021/ja02 57319

Nishiyama, Y., Sugiyama, J., Chanzy, H., and Langan, P. (2003). Crystal structure and hydrogen bonding system in cellulose $\mathrm{I} \alpha$ from synchrotron X-ray and neutron fiber diffraction. J. Am. Chem. Soc. 125, 14300-14306. doi: 10.1021/ ja037055w

Nixon, B. T., Mansouri, K., Singh, A., Du, J., Davis, J. K., Lee, J.-G., et al. (2016). Comparative structural and computational analysis supports eighteen cellulose synthases in the plant cellulose synthesis complex. Sci. Rep. 6:28696. doi: 10 . 1038/srep28696
Noori, M. S., and Karimi, K. (2016). Chemical and structural analysis of alkali pretreated pinewood for efficient ethanol production. RSC Adv. 6, 65683-65690. doi: 10.1039/C6RA11486E

O’Connor, R. T., DuPré, E. F., and Mitcham, D. (1958). Applications of infrared absorption spectroscopy to investigations of cotton and modified cottons: part I: physical and crystalline modifications and oxidation. Textile Res. J. 28, 382-392. doi: $10.1177 / 004051755802800503$

O’Neill, H., Pingali, S. V., Petridis, L., He, J., Mamontov, E., Hong, L., et al. (2017). Dynamics of water bound to crystalline cellulose. Sci. Rep. 7:11840. doi: 10.1038/s41598-017-12035-w

O'Sullivan, A. C. (1997). Cellulose: the structure slowly unravels. Cellulose 4, 173-207. doi: 10.1023/A:1018431705579

Page, D. H. (1969). A method for determining the fibrillar angle in wood tracheids. J. Microsc. 90, 137-143. doi: 10.1111/j.1365-2818.1969.tb00701.x

Park, S., Baker, J. O., Himmel, M. E., Parilla, P. A., and Johnson, D. K. (2010). Cellulose crystallinity index: measurement techniques and their impact on interpreting cellulase performance. Biotechnol. Biofuels 3:10. doi: 10.1186/17546834-3-10

Penttilä, P. A., Várnai, A., Fernández, M., Kontro, I., Liljeström, V., Lindner, P., et al. (2013). Small-angle scattering study of structural changes in the microfibril network of nanocellulose during enzymatic hydrolysis. Cellulose 20, 1031-1040. doi: 10.1007/s10570-013-9899-1

Penttilä, P. A., Várnai, A., Leppänen, K., Peura, M., Kallonen, A., Jääskeläinen, P., et al. (2010). Changes in submicrometer structure of enzymatically hydrolyzed microcrystalline cellulose. Biomacromolecules 11, 1111-1117. doi: 10.1021/ bm1001119

Peura, M., Müller, M., Serimaa, R., Vainio, U., Sarén, M.-P., Saranpää, P., et al. (2005). Structural studies of single wood cell walls by synchrotron X-ray microdiffraction and polarised light microscopy. Nuclear Instru. Methods Phys. Res. Sec. B 238, 16-20. doi: 10.1016/j.nimb.2005.06.011

Peura, M., Müller, M., Vainio, U., Sarén, M.-P., Saranpää, P., and Serimaa, R. (2007). X-ray microdiffraction reveals the orientation of cellulose microfibrils and the size of cellulose crystallites in single Norway spruce tracheids. Trees 22:49. doi: 10.1007/s00468-007-0168-5

Phyo, P., Wang, T., Xiao, C., Anderson, C. T., and Hong, M. (2017). Effects of pectin molecular weight changes on the structure, dynamics, and polysaccharide interactions of primary cell walls of Arabidopsis thaliana: insights from solid-state NMR. Biomacromolecules 18, 2937-2950. doi: 10.1021/ acs.biomac.7b00888

Pingali, S. V., O’Neill, H. M., Nishiyama, Y., He, L., Melnichenko, Y. B., Urban, V., et al. (2014). Morphological changes in the cellulose and lignin components of biomass occur at different stages during steam pretreatment. Cellulose 21, 873-878. doi: 10.1007/s10570-013-0162-6

Pingali, S. V., Urban, V. S., Heller, W. T., McGaughey, J., O’Neill, H., Foston, M., et al. (2010). Breakdown of cell wall nanostructure in dilute acid pretreated biomass. Biomacromolecules 11, 2329-2335. doi: 10.1021/ bm100455h

Poletto, M., Ornaghi, H. L., and Zattera, A. J. (2014). Native cellulose: structure, characterization and thermal properties. Materials 7, 6105-6119. doi: 10.3390/ ma7096105

Porter Stephanie, E., Donohoe Bryon, S., Beery Kyle, E., Xu, Q., Ding, S. Y., Vinzant Todd, B., et al. (2007). Microscopic analysis of corn fiber using starchand cellulose-specific molecular probes. Biotechnol. Bioeng. 98, 123-131. doi: 10.1002/bit.21409

Prater, C. B., Butt, H. J., and Hansma, P. K. (1990). Atomic force microscopy. Nature 345:839. doi: 10.1038/345839a0

Preston, R. D. (1934). The organization of the cell wall of the conifer tracheid. Philos. Trans. R. Soc. Lond. Ser. B Biol. Sci. 224, 131-174.

Reis, D., Vian, B., Chanzy, H., and Roland, J.-C. (1991). Liquid crystal-type assembly of native cellulose-glucuronoxylans extracted from plant cell wall. Biol. Cell 73, 173-178. doi: 10.1016/0248-4900(91)90100-2

Reiterer, A., Jakob, H. F., Stanzl-Tschegg, S. E., and Fratzl, P. (1998). Spiral angle of elementary cellulose fibrils in cell walls of Picea abies determined by small-angle x-ray scattering. Wood Sci. Technol. 32, 335-345. doi: 10.1007/ BF00702790

Revol, J. F. (1982). On the cross-sectional shape of cellulose crystallites in Valonia ventricosa. Carbohydr. Polym. 2, 123-134. doi: 10.1016/0144-8617(82)90058-3 
Riekel, C. (2000). New avenues in x-ray microbeam experiments. Rep. Prog. Phys. 63, 233-262. doi: 10.1088/0034-4885/63/3/201

Rivnay, J., Mannsfeld, S. C. B., Miller, C. E., Salleo, A., and Toney, M. F. (2012). Quantitative determination of organic semiconductor microstructure from the molecular to device scale. Chem. Rev. 112, 5488-5519. doi: 10.1021/cr3001109

Rondeau-Mouro, C., Bouchet, B., Pontoire, B., Robert, P., Mazoyer, J., and Buléon, A. (2003). Structural features and potential texturising properties of lemon and maize cellulose microfibrils. Carbohydr. Polym. 53, 241-252. doi: 10.1016/S0144-8617(03)00069-9

Ruland, W. (1961). X-ray determination of crystallinity and diffuse disorder scattering. Acta Crystallogr. 14, 1180-1185. doi: 10.1107/S0365110X61003429

Sahlberg, U., Salmén, L., and Oscarsson, A. (1997). The fibrillar orientation in the S2-layer of wood fibres as determined by X-ray diffraction analysis. Wood Sci. Technol. 31, 77-86. doi: 10.1007/BF00705923

Sandquist, D., Filonova, L., Schantz, L., Ohlin, M., and Daniel, G. (2010). Microdistribution of xyloglucan in differentiating poplar cells. Bioresources 5, 796-807.

Sant'Anna, C., and de Souza, W. L. (2012). "Microscopy as a tool to follow deconstruction of lignocellulosic biomass," in Current Microscopy Contributions to Advanced in Science and Technology, ed. A. Méndez-Vilas (Badajoz: Formatex), 639-645.

Sarkar, P., Bosneaga, E., and Auer, M. (2009). Plant cell walls throughout evolution: towards a molecular understanding of their design principles. J. Exp. Bot. 60, 3615-3635. doi: 10.1093/jxb/erp245

Sarkar, P., Bosneaga, E., Yap, E. G. Jr., Das, J., Tsai, W.-T., Cabal, A., et al. (2014). Electron tomography of cryo-immobilized plant tissue: a novel approach to studying 3D macromolecular architecture of mature plant cell walls in situ. PLoS One 9:e106928. doi: 10.1371/journal.pone.0106928

Saxe, F., Eder, M., Benecke, G., Aichmayer, B., Fratzl, P., Burgert, I., et al. (2014). Measuring the distribution of cellulose microfibril angles in primary cell walls by small angle X-ray scattering. Plant Methods 10:25. doi: 10.1186/1746-4811$10-25$

Scallan, A. M. (1971). A quantitative picture of the fringed micellar model of cellulose. Textile Res. J. 41, 647-653. doi: 10.1177/004051757104100802

Schenzel, K., Fischer, S., and Brendler, E. (2005). New method for determining the degree of cellulose I crystallinity by means of FT raman spectroscopy. Cellulose 12, 223-231. doi: 10.1007/s10570-004-3885-6

Schimleck, L. R., Evans, R., Ilic, J., and Matheson, A. C. (2002). Estimation of wood stiffness of increment cores by near-infrared spectroscopy. Can. J. Forest Res. 32, 129-135. doi: 10.1139/x01-176

Schimleck, L. R., Kube, P. D., Raymond, C. A., Michell, A. J., and French, J. (2005). Estimation of whole-tree kraft pulp yield of Eucalyptus nitens using near-infrared spectra collected from increment cores. Can. J. Forest Res. 35, 2797-2805. doi: 10.1139/x05-193

Schneider, C. A., Rasband, W. S., and Eliceiri, K. W. (2012). NIH Image to ImageJ: 25 years of image analysis. Nat. Methods 9, 671-675. doi: 10.1038/nmeth.2089

Scott, T. A., and Melvin, E. H. (1953). Determination of dextran with anthrone. Anal. Chem. 25, 1656-1661. doi: 10.1021/ac60083a023

Segal, L., Creely, J. J., Martin, A. E., and Conrad, C. M. (1959). An empirical method for estimating the degree of crystallinity of native cellulose using the X-Ray diffractometer. Textile Res. J. 29, 786-794. doi: 10.1177/004051755902 901003

Senft, J. F., and Bendetsen, B. A. (1985). Measuring microfibrillar angles using light microscopy. Wood Fibre Sci. 17:4.

Simmons, T. J., Mortimer, J. C., Bernardinelli, O. D., Pöppler, A.-C., Brown, S. P., deAzevedo, E. R., et al. (2016). Folding of xylan onto cellulose fibrils in plant cell walls revealed by solid-state NMR. Nat. Commun. 7:13902. doi: 10.1038/ ncomms 13902

Široký, J., Benians, T. A. S., Russell, S. J., Bechtold, T., Paul Knox, J., and Blackburn, R. S. (2012). Analysis of crystallinity changes in cellulose II polymers using carbohydrate-binding modules. Carbohydr. Polym. 89, 213-221. doi: 10.1016/ j.carbpol.2012.02.073

Sponsler, O. L. (1928). The molecular structure of the cell wall of fibers. A summary of X-ray investigations. Am. J. Bot. 15, 525-536. doi: 10.1002/j.1537-2197.1928. tb09447.x

Strachan, C. J., Taday, P. F., Newnham, D. A., Gordon, K. C., Zeitler, J. A., Pepper, M., et al. (2005). Using terahertz pulsed spectroscopy to quantify pharmaceutical polymorphism and crystallinity. J. Pharm. Sci. 94, 837-846. doi: 10.1002/jps.20281

Sugiyama, J., Harada, H., Fujiyoshi, Y., and Uyeda, N. (1985). Lattice images from ultrathin sections of cellulose microfibrils in the cell wall of Valonia macrophysa Kütz. Planta 166, 161-168. doi: 10.1007/BF00397343

Sugiyama, J., Persson, J., and Chanzy, H. (1991a). Combined infrared and electron diffraction study of the polymorphism of native celluloses. Macromolecules 24, 2461-2466. doi: 10.1021/ma00009a050

Sugiyama, J., Vuong, R., and Chanzy, H. (1991b). Electron diffraction study on the two crystalline phases occurring in native cellulose from an algal cell wall. Macromolecules 24, 4168-4175. doi: 10.1021/ma00014a033

Suzuki, H., and Kamiyama, T. (2004). Structure of cellulose microfibrils and the hydration effect in Cryptomeria japonica: a small-angle X-ray scattering study. J. Wood Sci. 50, 351-357. doi: 10.1007/s10086-003-0567-1

Svedström, K., Bjurhager, I., Kallonen, A., Peura, M., and Serimaa, R. (2012). "Structure of oak wood from the Swedish warship Vasa revealed by X-ray scattering and microtomography. Holzforschung 66, 355-363. doi: 10.1515/hf. 2011.157

Thimm, J. C., Burritt, D. J., Ducker, W. A., and Melton, L. D. (2000). Celery (Apium graveolens L.) parenchyma cell walls examined by atomic force microscopy: effect of dehydration on cellulose microfibrils. Planta 212, 25-32. doi: 10.1007/ s004250000359

Thomas, L. H., Forsyth, V. T., Šturcová, A., Kennedy, C. J., May, R. P., Altaner, C. M., et al. (2013). Structure of cellulose microfibrils in primary cell walls from collenchyma. Plant Physiol. 161, 465-476. doi: 10.1104/pp.112.206359

Thomson, C. I., Lowe, R. M., and Ragauskas, A. J. (2007). Imaging cellulose fibre interfaces with fluorescence microscopy and resonance energy transfer. Carbohydr. Polym. 69, 799-804. doi: 10.1016/j.carbpol.2007.01.023

Thygesen, A., Oddershede, J., Lilholt, H., Thomsen, A. B., and Ståhl, K. (2005). On the determination of crystallinity and cellulose content in plant fibres. Cellulose 12:563. doi: 10.1007/s10570-005-9001-8

Tittmann, B., and Xi, X. (2014). "Imaging and quantitative data acquisition of biological cell walls with atomic force microscopy and scanning acoustic microscopy," in Microscopy: Advances in Scientific Research and Education, ed. A. Mèndez-Vilas (Badajoz: Formatex Research Center), 161-172.

Tokoh, C., Takabe, K., Fujita, M., and Saiki, H. (1998). Cellulose synthesized by Acetobacter xylinum in the presence of acetyl glucomannan. Cellulose 5, 249-261. doi: 10.1023/A:1009211927183

Tokoh, C., Takabe, K. J., and Fujita, M. (2002). Cellulose synthesized by Acetobacter xylinum in the presence of plant cell wall polysaccharides. Cellulose 9, 65-74. doi: 10.1023/A:1015827121927

Updegraff, D. M. (1969). Semimicro determination of cellulose in biological materials. Anal. Biochem. 32, 420-424. doi: 10.1016/S0003-2697(69)80 009-6

Usov, I., and Mezzenga, R. (2015). FiberApp: an open-source software for tracking and analyzing polymers, filaments, biomacromolecules, and fibrous objects. Macromolecules 48, 1269-1280. doi: 10.1021/ma50 $2264 \mathrm{c}$

van der Wel, N. N., Putman, C. A. J., van Noort, S. J. T., de Grooth, B. G., and Emons, A. M. C. (1996). Atomic force microscopy of pollen grains, cellulose microfibrils, and protoplasts. Protoplasma 194, 29-39. doi: 10.1007/ BF01273165

Vandavasi, V. G., Putnam, D. K., Zhang, Q., Petridis, L., Heller, W. T., Nixon, B. T., et al. (2016). A Structural Study of CESA1 catalytic domain of arabidopsis cellulose synthesis complex: evidence for CESA trimers. Plant Physiol. 170, 123-135. doi: 10.1104/pp.15.01356

VanderHart, D. L., and Atalla, R. H. (1984). Studies of microstructure in native celluloses using solid-state carbon-13 NMR. Macromolecules 17, 1465-1472. doi: $10.1021 / \mathrm{ma} 00138 \mathrm{a} 009$

Vieira, F. S., and Pasquini, C. (2014). Determination of cellulose crystallinity by terahertz-time domain spectroscopy. Anal. Chem. 86, 3780-3786. doi: 10.1021/ ac4035746

Virgili, J. M., Tao, Y. F., Kortright, J. B., Balsara, N. P., and Segalman, R. A. (2007). Analysis of order formation in block copolymer thin films using resonant soft X-ray scattering. Macromolecules 40, 2092-2099. doi: 10.1021/ ma061734k 
Wada, M., Okano, T., and Sugiyama, J. (1997). Synchrotron-radiated X-ray and neutron diffraction study of native cellulose. Cellulose 4, 221-232. doi: 10.1023/ A: 1018435806488

Wang, J., Hitchcock, A. P., Karunakaran, C., Prange, A., Franz, B., Harkness, T., et al. (2011). 3D chemical and elemental imaging by STXM spectrotomography. AIP Conf. Proc. 1365, 215-218. doi: 10.1063/1.3625342

Wang, T., and Hong, M. (2016). Solid-state NMR investigations of cellulose structure and interactions with matrix polysaccharides in plant primary cell walls. J. Exp. Bot. 67, 503-514. doi: 10.1093/jxb/erv416

Wang, T., Zabotina, O., and Hong, M. (2012). Pectin-cellulose interactions in the arabidopsis primary cell wall from two-dimensional magic-angle-spinning solid-state nuclear magnetic resonance. Biochemistry 51, 9846-9856. doi: 10. 1021/bi3015532

Wardrop, A. B., and Preston, R. D. (1947). Organisation of the cell walls of tracheids and wood fibres. Nature 160:911. doi: 10.1038/160911a0

Warwick, T., Franck, K., Kortright, J. B., Meigs, G., Moronne, M., Myneni, S., et al. (1998). A scanning transmission x-ray microscope for materials science spectromicroscopy at the advanced light source. Rev. Sci. Instr. 69, 2964-2973. doi: 10.1063/1.1149041

Westphal, V., Lauterbach, M. A., Nicola, A. D., and Hell, S. W. (2007). Dynamic farfield fluorescence nanoscopy. New J. Phys. 9:435. doi: 10.1101/pdb.prot069260

White, P. B., Wang, T., Park, Y. B., Cosgrove, D. J., and Hong, M. (2014). Waterpolysaccharide interactions in the primary cell wall of arabidopsis thaliana from polarization transfer solid-state NMR. J. Am. Chem. Soc. 136, 10399-10409. doi: $10.1021 /$ ja504108h

Xiao, C., and Anderson, C. T. (2016). Interconnections between cell wall polymers, wall mechanics, and cortical microtubules: teasing out causes and consequences. Plant Signal. Behav. 11:e1215396. doi: 10.1080/15592324.2016. 1215396

Xiao, C., Zhang, T., Zheng, Y., Cosgrove, D. J., and Anderson, C. T. (2016). Xyloglucan deficiency disrupts microtubule stability and cellulose biosynthesis in Arabidopsis, altering cell growth and morphogenesis. Plant Physiol. 170, 234-249. doi: 10.1104/pp.15.01395

Xu, T., Vavylonis, D., Tsai, F.-C., Koenderink, G. H., Nie, W., Yusuf, E., et al. (2015). SOAX: a software for quantification of 3D biopolymer networks. Sci. Rep. 5:9081. doi: 10.1038/srep09081

Yamamoto, H., and Horii, F. (1993). CPMAS carbon-13 NMR analysis of the crystal transformation induced for Valonia cellulose by annealing at high temperatures. Macromolecules 26, 1313-1317. doi: 10.1021/ma00058a020

Yamamoto, H., Horii, F., and Hirai, A. (1996). In situ crystallization of bacterial cellulose II. Influences of different polymeric additives on the formation of celluloses I $\alpha$ and I $\beta$ at the early stage of incubation. Cellulose 3, 229-242. doi: $10.1007 / \mathrm{BF} 02228804$

Yamamoto, H., and Horn, F. (1994). In Situ crystallization of bacterial cellulose I. Influences of polymeric additives, stirring and temperature on the formation celluloses I $\alpha$ and I $\beta$ as revealed by cross polarization/magic angle spinning (CP/MAS)13C NMR spectroscopy. Cellulose 1, 57-66. doi: 10.1007/ BF00818798
Yamamoto, H., Okuyama, T., and Yoshida, M. (1993). Method of determining the mean microfibril angle of wood over a wide range by the improved Cave's method. Mokuzai Gakkaishi 39, 375-381.

Yarbrough, J. M., Himmel, M. E., and Ding, S.-Y. (2009). Plant cell wall characterization using scanning probe microscopy techniques. Biotechnol. Biofuels 2:17. doi: 10.1186/1754-6834-2-17

Ye, D., Kiemle, S. N., Rongpipi, S., Wang, X., Wang, C., Cosgrove, D. J., et al. (2018a). Resonant soft X-ray scattering reveals cellulose microfibril spacing in plant primary cell walls. Sci. Rep. 8:12449. doi: 10.1038/s41598-01831024-1

Ye, D., Le, T. P., Kuei, B., Zhu, C., Zwart, P. H., Wang, C., et al. (2018b). Resonant soft X-Ray scattering provides protein structure with chemical specificity. Structure 26, 1513.e3-1521.e3. doi: 10.1016/j.str.2018.07.018

Zhang, T., Mahgsoudy-Louyeh, S., Tittmann, B., and Cosgrove, D. J. (2014). Visualization of the nanoscale pattern of recently-deposited cellulose microfibrils and matrix materials in never-dried primary walls of the onion epidermis. Cellulose 21, 853-862. doi: 10.1007/s10570-013-9996-1

Zhang, T., Vavylonis, D., Durachko, D. M., and Cosgrove, D. J. (2017). Nanoscale movements of cellulose microfibrils in primary cell walls. Nat. Plants 3:17056. doi: 10.1038/nplants.2017.56

Zhang, T., Zheng, Y., and Cosgrove, D. J. (2016). Spatial organization of cellulose microfibrils and matrix polysaccharides in primary plant cell walls as imaged by multichannel atomic force microscopy. Plant J. 85, 179-192. doi: 10.1111/tpj. 13102

Zhang, Y., Inouye, H., Yang, L., Himmel, M. E., Tucker, M., and Makowski, L. (2015). Breakdown of hierarchical architecture in cellulose during dilute acid pretreatments. Cellulose 22, 1495-1504. doi: 10.1007/s10570-0150592-4

Zheng, Y., Wang, X., Chen, Y., Wagner, E., and Cosgrove, D. J. (2018). Xyloglucan in the primary cell wall: assessment by FESEM, selective enzyme digestions and nanogold affinity tags. Plant J. 93, 211-226. doi: 10.1111/tpj.13778

Zobel, B. J. (1961). Inheritance of wood properties in conifers. Silvae Genet. 10, 65-70.

Zuluaga, R., Putaux, J.-L., Cruz, J., Vélez, J., Mondragon, I., and Gañán, P. (2009). Cellulose microfibrils from banana rachis: effect of alkaline treatments on structural and morphological features. Carbohydr. Polym. 76, 51-59. doi: 10. 1016/j.carbpol.2008.09.024

Conflict of Interest Statement: The authors declare that the research was conducted in the absence of any commercial or financial relationships that could be construed as a potential conflict of interest.

Copyright (c) 2019 Rongpipi, Ye, Gomez and Gomez. This is an open-access article distributed under the terms of the Creative Commons Attribution License (CC BY). The use, distribution or reproduction in other forums is permitted, provided the original author(s) and the copyright owner(s) are credited and that the original publication in this journal is cited, in accordance with accepted academic practice. No use, distribution or reproduction is permitted which does not comply with these terms. 